OPEN ACCESS

Edited by:

Christian Gonzalez-Billault,

University of Chile, Chile

Reviewed by:

Aslihan Terzi,

Stanford University, United States

Andréa Cristina Paula-Lima,

University of Chile, Chile

*Correspondence:

Frederik Vilhardt

vilhardt@sund.ku.dk

Received: 05 July 2021 Accepted: 08 October 2021 Published: 05 November 2021

Citation:

Villegas L, Nørremølle A, Freude $K$ and Vilhardt $F$ (2021) Nicotinamide Adenine Dinucleotide Phosphate Oxidases Are Everywhere in Brain Disease, but Not in Huntington's

Disease?

Front. Aging Neurosci. 13:736734. doi: 10.3389/fnagi.2021.736734

\section{Nicotinamide Adenine Dinucleotide Phosphate Oxidases Are Everywhere in Brain Disease, but Not in Huntington's Disease?}

\author{
Luisana Villegas ${ }^{1}$, Anne Nørremølle ${ }^{1}, K_{\text {Kristine Freude }}^{2}$ and Frederik Vilhardt ${ }^{1 *}$ \\ ${ }^{1}$ Department of Cellular and Molecular Medicine, University of Copenhagen, Copenhagen, Denmark, ${ }^{2}$ Department \\ of Veterinary and Animal Sciences, Faculty of Health and Medical Sciences, University of Copenhagen, Frederiksberg, \\ Denmark
}

Huntington's disease (HD) is an inherited neurodegenerative disorder characterized by neuronal loss and tissue atrophy mainly in the striatum and cortex. In the early stages of the disease, impairment of neuronal function, synaptic dysfunction and white matter loss precedes neuronal death itself. Relative to other neurodegenerative diseases such as Alzheimer's and Parkinson's disease and Amyotrophic Lateral Sclerosis, where the effects of either microglia or NADPH oxidases (NOXs) are recognized as important contributors to disease pathogenesis and progression, there is a pronounced lack of information in HD. This information void contrasts with evidence from human HD patients where blood monocytes and microglia are activated well before HD clinical symptoms (PET scans), and the clear signs of oxidative stress and inflammation in post mortem HD brain. Habitually, NOX activity and oxidative stress in the central nervous system (CNS) are equated with microglia, but research of the last two decades has carved out important roles for NOX enzyme function in neurons. Here, we will convey recent information about the function of NOX enzymes in neurons, and contemplate on putative roles of neuronal NOX in HD. We will focus on NOX-produced reactive oxygen species (ROS) as redox signaling molecules in/among neurons, and the specific roles of NOXs in important processes such as neurogenesis and lineage specification, neurite outgrowth and growth cone dynamics, and synaptic plasticity where NMDAR-dependent signaling, and long-term depression/potentiation are redoxregulated phenomena. HD animal models and induced pluripotent stem cell (iPSC) studies have made it clear that the very same physiological processes are also affected in HD, and we will speculate on possible roles for NOX in the pathogenesis and development of disease. Finally, we also take into account the limited information on microglia in HD and relate this to any contribution of NOX enzymes.

Keywords: Huntington's (disease), NADPH (nicotinamide adenine dinucleotide phosphate) oxidase, neuron, Huntingtin (HTT), NMDAR (NMDA receptor), LTP (long term potentiation), LTD (long term depression) 


\section{INTRODUCTION}

Microglia express NADPH oxidases (NOX) and in many neurodegenerative diseases (NDDs) microglia activation and the ensuing oxidant production through NOX2, together with proinflammatory response including cytokine secretion, play major roles in disease pathogenesis (Block et al., 2007; Tejera and Heneka, 2019). However, more recently NOX expression in neurons have attracted attention in physiological and pathological settings (Nayernia et al., 2014). Hence, changes in NOX activity in NDD's are not necessarily restricted to microglia but may also take place in neurons as a cell-autonomous mechanism, all though evidence for direct involvement of neuronal NOX isoforms in NDD is still scarce.

Here, we will convey recent information about the function of NOXs in the Central Nervous System (CNS) and contemplate on the putative role of neuronal NOX in the neurodegenerative disorder Huntington's Disease (HD). We will focus on NOXproduced reactive oxygen species (ROS) as a signaling molecule in/among neurons and the specific roles of NOXs in important processes in the synapses and neurites. We will thus compare the processes where NOXs are involved to the pathogenic mechanisms of HD, asking if NOXs are likely to be players in the initial synaptic dysfunction that characterizes HD, as well as later in disease progression. Given the high expression of NOX in microglia, we will also review the limited literature of NOX derived ROS in this particular cell type in relation to HD.

\section{NOX AND OXIDANTS: OXIDATIVE STRESS VERSUS REDOX SIGNALING}

Before we delve into the intricacies of NOX activity and oxidant production in neurons it is justified to briefly put into perspective the phenomenon of oxidative eustress versus oxidative stress. Oxidative stress is a condition with an imbalance in oxidant and antioxidant production, such that antioxidant defense mechanisms are overwhelmed by excessive oxidants. As such, oxidative stress is thought to be an inherent property of many neurodegenerative diseases (Singh et al., 2019). In the early days, oxidative stress was synonymous with the indiscriminate and irreversible oxidation and destruction of biomolecules and detected as molecular signs of oxidative modification of biomolecules (nitrosylation, sulfonation, carbonylation, and peroxidation). Today we know that under physiological circumstances cellular redox balance (oxidative eustress) is tightly maintained to allow oxidants to act as signaling molecules typically by their reversible oxidation of low pKa cysteines in target redox proteins, with a wide spectrum of functions that are still not fully discovered (Sies and Jones, 2020). Therefore, the concept of oxidative stress has since been expanded to account for the fact that even small perturbations of local or global redox milieu can seriously disrupt redox signaling circuits (Sies, 2014).

The CNS itself is highly susceptible to oxidative stress due to its fast rate of oxygen consumption and high iron content (Bresgen and Eckl, 2015), resulting in an increased generation of ROS.
In addition, the antioxidant machinery that exists to counteract oxidative stress has lower levels of expression in the CNS, and in neurons particularly (Kamat et al., 2008; Teleanu et al., 2019). This relatively low neuronal antioxidant level could be due to a tradeoff; as ROS is required for exit from the neurogenic stem cell niche and neuronal induction (Nayernia et al., 2017), nerve cells habitually express low levels of nuclear factor erythroid 2related factor 2 (NRF2) (Bell et al., 2015), a major transcriptional regulator of antioxidant genes (Hardingham and Do, 2016).

\section{HUNTINGTON'S DISEASE}

HD is an autosomal dominant inherited, neurodegenerative disease caused by an expansion of a CAG repeat in exon 1 of the HD gene, encoding an elongated poly-glutamine stretch in the huntingtin protein (The Huntington Disease Collaborative Research Group, 1993). Symptoms of HD include motor, psychiatric and cognitive changes usually emerging in midlife (with an earlier onset in those patients with larger poly-glutamine expansions), progressing to eventually cause fatal multi-system failure. Death of neurons, in particular striatal medium spiny neurons (MSNs) and cortical projection neurons but also neuron populations in other brain regions, is a prominent feature in late-stage HD. The MSNs are gamma-aminobutyric acid-ergic (GABAergic) inhibitory neurons receiving glutamatergic input from cortex, as well as dopaminergic input from the substantia nigra pars compacta (Blumenstock and Dudanova, 2020). MSNs affect the activity of neurons in the thalamus and cortex, thereby regulating the initiation and execution of movements. MSNs are divided in two classes, where the MSNs of the direct pathway project to output nuclei in the substantia nigra pars reticulate and the internal part of the globus pallidus (which connect to the thalamus), whereas the MSNs of the indirect pathway project to inhibitory neurons in the external part of the globus pallidus. These inhibitory neurons in turn affects the same output nuclei as the direct pathway, leading to opposing effect on the activity of these: the MSN direct pathway inhibits, and the MSN indirect pathway activates, the GABAergic neurons of the substantia nigra pars reticulate and the internal part of the globus pallidus (Blumenstock and Dudanova, 2020). In HD progression, the MSNs of the indirect pathway are the first to degenerate, which correlate well with the prominent involuntary movements (hyperkinesia) which are among the early symptoms of HD.

Before reaching final stage of neurodegeneration, at which symptoms of HD are evident and widespread, patients endure an extended period of gradual disease progression. Increasing neuronal dysfunction, specifically synaptic dysfunctions such as impaired synaptic plasticity and dysregulation of synaptic transmission are observed, most likely starting already at the prodromal, pre-symptomatic phase (Smith-Dijak et al., 2019). In particular, aberration of cortico-striatal connections are prominent and may (at least in part) explain the early hyperkinetic motor symptoms of HD (Plotkin and Surmeier, 2015). Because motor symptoms of the disease manifest before there is overt nerve cell death, HD is sometimes referred to as a 'synaptopathy'. Indeed, both cortical and striatal neurons of 
HD mouse models display synaptic dysfunction at very early, pre-symptomatic stages (reviewed in Cepeda and Levine (2020)). These functional changes are supported by proteomic analysis, in which early HD-related changes predominantly occur in proteins involved in synaptic function (Skotte et al., 2018; Sapp et al., 2020). According to the "dying-back" theory, such early synaptic changes can lead to synapse and neurite degeneration and loss, which may eventually result in neuronal death (Han et al., 2010).

Huntingtin (Htt) is ubiquitously expressed and localizes mainly in the cytoplasm, but also in the nucleus; within the cell, huntingtin associates with numerous cellular structures and molecules (Saudou and Humbert, 2016). Htt has a tremendous number of protein interaction partners $(>100)$, which perhaps point to a general function of $\mathrm{Htt}$ as scaffolding protein, and in part dictates the many proposed roles of $\mathrm{Htt}$ as well as the subcellular localization of $\mathrm{Htt}$. In neurons $\mathrm{Htt}$ can be found along neurites and in terminals, in part due to its interaction with the dynein-dynactin complex (Rui et al., 2015), which drives vesicular transport along microtubules. Htt has a major role in the regulation of autophagosome (Wong and Holzbaur, 2014; Rui et al., 2015), endosomal (Caviston et al., 2007), or stress granule (Ma et al., 2011) dynamics and positioning, and the very same processes and organelles (among others) are affected adversely by $\mathrm{mHtt}$ (Gunawardena et al., 2003; Morfini et al., 2009; Martinez-Vicente et al., 2010; Wong and Holzbaur, 2014). Htt also interacts with the actin cytoskeleton through binding to a-actinin, an actin anchoring and cross-linking protein, and in fibroblasts co-localizes with actin stress fibers and adhesion structures (Tousley et al., 2019a). In mHtt-expressing cells, a large fractional area of the cytosol is occupied by spherical inclusion bodies of aggregated $\mathrm{mHtt}$ surrounded by markers of autophagy (p62/SQSTM1) and intermediate filaments. Inclusion formation can have negative effects on organelles (Bauerlein et al., 2017), trafficking systems (Woerner et al., 2016), and cause the sequestration of other glutamine-rich and prion domain-containing proteins (Ramdzan et al., 2017) but may also have cytoprotective function (Miller et al., 2010).

In HD patients, mutant huntingtin is expressed throughout life, including during embryogenesis (Saudou and Humbert, 2016). In line with this, the expression of mutant huntingtin has been shown to affect not only adult neuronal function, leading to neurodegeneration, but also neurodevelopment including neuronal differentiation and establishment of connectivity through neurite outgrowth (Conforti et al., 2018; Barnat et al., 2020; van der Plas et al., 2020). Intriguingly, mouse models expressing mutant huntingtin solely during embryonic and early development develop HD-like symptoms (Molero et al., 2016). As hypothesized by $\mathrm{Lu}$ and $\mathrm{Lu}$, these data indicate that neurodevelopmental dysregulation may play an important role in HD pathogenesis developing in adulthood ( $\mathrm{Lu}$ and $\mathrm{Lu}, 2021$ ).

Although the initial cause of the pathology is known expression of huntingtin carrying an expanded poly-glutamine stretch - the downstream pathogenic processes are still not well understood. As excellently reviewed by Bates et al., mutant huntingtin has been shown to lead to (among others) transcriptional dysregulation, impairment of axonal vesicular transport, synaptic dysfunction and impaired mitochondrial function (Bates et al., 2015). In both human post mortem HD brain (Sorolla et al., 2008) and HD animal models (Bogdanov et al., 2001) there are tell-tale signs of oxidative stress, but focus has almost exclusively been on mitochondria-generated ROS (Zheng et al., 2018; Fão and Rego, 2021) ignoring the major oxidant producing enzymes, the family of NOXs (Brown and Borutaite, 2012; Lambeth and Neish, 2014; Sies and Jones, 2020).

\section{THE FAMILY OF NICOTINAMIDE ADENINE DINUCLEOTIDE PHOSPHATE OXIDASES}

NOXs are transmembrane, superoxide-producing enzyme complexes. Once activated, the NOX complexes transfer electrons from nicotinamide adenine dinucleotide phosphate (NADPH) in the cytosol to molecular oxygen on the other side of the membrane, thus producing superoxide $\left(\mathrm{O}_{2} \cdot{ }^{-}\right)$in the extracellular space or the topologically identical luminal space of organelles and vesicles. Superoxide quickly dismutation to hydrogen peroxide spontaneously, or more commonly at high levels of oxidants, via superoxide dismutase activity.

The NOX family is comprised of 7 isoforms (NOX1-5 and DUOX1-2) (Figure 1; Bedard and Krause, 2007). The first prototypical member of the family to be characterized was the classical phagocyte NADPH oxidase, now called NOX2, consisting of a membrane-anchored flavocytochrome $b_{558}$, itself composed of two membrane proteins gp91 ${ }^{\text {phox }}$ (also confusingly referred to as NOX2), containing heme redox relay stations for electron transfer, and p22 $2^{\text {phox }}$. Activation of the NOX2 enzyme involves further recruitment of four cytosolic proteins which translocate to the membrane: $\mathrm{p} 67^{\text {phox }}$ and the small GTP-binding protein Rac1/2, which together regulate electron transfer from NADPH to redox centers in gp91 phox , and $440^{\text {phox }}$ or $447^{\text {phox }}$ as organizers of assembly (Vignais, 2002). While introduction of dominant active Racl is sufficient to induce NOX activation in a heterologous cell model with NOX2 overexpression (Price et al., 2002), it is insufficient in phagocytes, where the critical step in NOX2 activation (at least in microglia) is phosphorylation of p47phox (Roepstorff et al., 2008). Multiple phosphorylation events on serines uncovers the latent $\mathrm{SH} 3$ domains of p47phox, making them available for binding to p22 ${ }^{\text {phox }}$ (Sumimoto et al., 1996). In addition, PX domains contained in the SH3 domains of $\mathrm{p}^{4} \mathrm{p}^{\text {phox }}$ and $\mathrm{p} 40^{\text {phox }}$ contributes to membrane recruitment through binding to phosphoinositide lipids (Zhan et al., 2002; Ago et al., 2003).

NOX1 consists of the membrane-anchored subunits NOX1 and p22 $2^{\text {phox }}$, which interacts with NOXO1 and NOXA1, homologs of $\mathrm{p} 47^{\text {phox }}$ and $\mathrm{p} 67^{\text {phox }}$, respectively, as well as Rac. Likewise, NOX3 interacts with $\mathrm{p} 22^{\text {phox }}$ in addition to NOXO1 (Cheng et al., 2004). In contrast, the NOX4-p22 phox complex, as well as the NOX5, DUOX1 and DUOX2 isoforms can be activated independently of cytosolic phox proteins (Bedard and Krause, 2007). NOX4 is thought to be constitutively active, while NOX5 

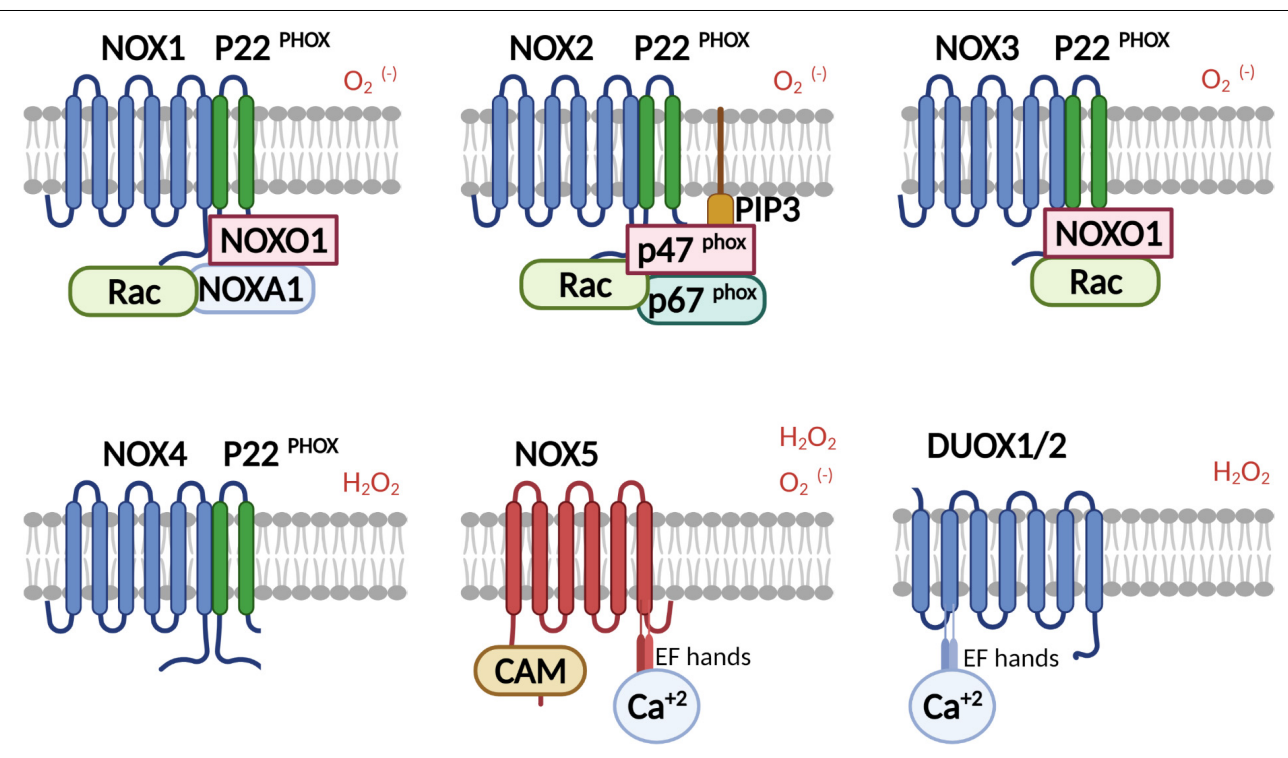

FIGURE 1 | Schematic representation of the family of NADPH oxidases. NOX isoforms and regulatory subunits: NOX1-3 are activated in the presence of cytosolic phox proteins, where PIP3 serves as a membrane anchor for p47phox in the case of NOX2 activation. NOX1-3, and NOX5 release superoxide (in some cases NOX5 also hydrogen peroxide), whereas NOX4 and the DUOXes release only hydrogen peroxide. NOX4 is constitutively active and is regulated by expression. NOX5 and DUOX1/2 are calcium dependent through calcium-calmodulin binding or by the direct binding of $\mathrm{Ca}^{2+}$ to EF-hands in DUOXes, respectively.

and DUOX1/2 have N-terminal extensions containing 2 to 4 EFhand $\mathrm{Ca}^{+2}$ binding domains allowing their activation through calcium sensing (Banfi et al., 2004) (see Figure 1 for schematic representation of NOX isoforms). Both NOX4 and the DUOX enzymes release hydrogen peroxide rather than superoxide.

NOX2, the classical phagocyte NADPH oxidase, is well known for its bactericidal role in innate immune defense (Nauseef, 2019), but with the advent of the NOX superfamily it was quickly realized that these enzymes occupies an important role as oxidant producers in an intricate network of cellular redox signaling circuits. Hydrogen peroxide is here believed to be the redoxrelevant signaling messenger, and controls the activity of target proteins typically by the reversible oxidation of low $\mathrm{pKa}$ cysteines or metal centers (Sies and Jones, 2020; Petersen et al., 2021). The redox targets are diverse, but for the purpose of this review it is worth mentioning that many ion channels, kinases, and phosphatases are regulated or modulated by hydrogen peroxide (Winterbourn, 2013; Sies, 2014; Sies and Jones, 2020).

In the CNS, mainly NOX2 and NOX4 isoforms are expressed under basal conditions, while other NOX isoforms can be induced by stimulation (Massaad and Klann, 2011; Nayernia et al., 2014). Different neuronal populations (cortical, hippocampal, hypothalamic paraventricular nucleus neurons, cerebellar granule neurons, neurons of the sympathetic system, parvalbumin-positive GABAergic interneurons) mainly express the phagocyte NOX2, but dopaminergic neurons express NOX1, and dorsal root ganglion neurons (DRGs) express NOX4 (Massaad and Klann, 2011; Nayernia et al., 2014; Sorce et al., 2017). Glial cells and the vascular compartment also express NOX isoforms (Nayernia et al., 2014), and in particular microglia express NOX2. Because only NOX2 function in CNS has been addressed with some weight, we will in the following sections focus on neuronal expression of this isoform in CNS neurons and microglia.

\section{SUBCELLULAR LOCALIZATION OF NOX IN NEURONS}

Virtually all cells of our body express NOX isoforms. Many cell types express more than one NOX isoform, and despite their high homology, they localize differentially in a cell typespecific manner. For example, in endothelial cells, NOX1 is present in caveolae while NOX4 segregates to focal adhesions (Helmcke et al., 2009); in microglia, NOX1 seems to reside in lysosomes (Cheret et al., 2008), while NOX2 is localized to agonist-responsive secretory vesicles and the plasma membrane (Ejlerskov et al., 2012). Because of the large and polarized shape of neurons it is reasonable to assume that the same can occur in neurons, such that separate redox signaling circuits can function simultaneously in the same cell (see discussion in Petersen et al. (2021)). No sorting receptors for NOX have been identified, and there are very few clues to the differential and cell-specific subcellular distribution of the different NOX isoforms, as very few interaction partners of NOX family members have been identified (Park et al., 2004; Ikeda et al., 2005; Gianni et al., 2009). In microglia, the small GTPases Rab27A/B determine the distribution of intracellular to cell surface-resident NOX2 (Ejlerskov et al., 2012), which in essence determines the release to the surroundings of either hydrogen peroxide or superoxide, respectively, because of their different membrane permeabilities.

In the following sections, we have compiled the available data of NOX2 localization in neurons (summarized in Table 1). The data have been compiled from ultrastructural studies, most 
TABLE 1 | The subcellular distribution of NOX2, p22 phox, and p47phox observed by immunolabeling in neurons (Wang G. et al., 2004; Glass et al., 2006; Brennan et al., 2009; Girouard et al., 2009; Minnella et al., 2018).

\begin{tabular}{|c|c|c|}
\hline \multirow[t]{7}{*}{ Somata } & Plasma membrane & gp91 phox (Wang G. et al., 2004; Glass et al., 2006), p47 phox (Coleman et al., 2013) \\
\hline & Mitochondria & gp91 phox (Wang G. et al., 2004; Girouard et al., 2009; Coleman et al., 2013) \\
\hline & MVBs & gp91 phox (Glass et al., 2006), p47 phox (Coleman et al., 2013) \\
\hline & Vesicular organelles of the cytoplasm & $\begin{array}{l}\text { gp91 } \\
\text { (Colemax }\left(\text { Glass et al., 2006; Girouard et al., 2009), p22 }{ }^{\text {phox }}, \text { p4 } 47^{\text {phox }} \text { (Glass et al., 2006) p47 }\right.\end{array}$ \\
\hline & Rough ER & gp91 ${ }^{\text {phox }}$ (Glass et al., 2006), p47 phox (Coleman et al., 2013) \\
\hline & Golgi Complex & gp91 phox (Wang G. et al., 2004), p22 phox (Glass et al., 2006), p47 phox (Glass et al., 2006) \\
\hline & Cytosol & p47 phox (Coleman et al., 2013) \\
\hline \multirow[t]{8}{*}{ Dendrites } & Plasma membrane & gp91 phox (Glass et al., 2006), p47 phox (Coleman et al., 2013) \\
\hline & Perisynaptic plasma membrane & $\begin{array}{l}\text { gp91 }{ }^{\text {phox }} \text { (Glass et al., 2006; Wang et al., 2015), p22 } \\
\text { et al., 2006; Coleman et al., 2013) }\end{array}$ \\
\hline & Mitochondria & gp91 phox (Glass et al., 2006), p22 phox (Glass et al., 2006), p47 phox (Coleman et al., 2013) \\
\hline & Smooth ER & gp91 phox (Wang G. et al., 2004) \\
\hline & MVBs & gp91 ${ }^{\text {phox }}$ (Wang G. et al., 2004) \\
\hline & Vesicular organelles of the cytoplasm & gp91 phox (Glass et al., 2006), p22 ${ }^{\text {phox }}$, p47phox (Glass et al., 2006) \\
\hline & Undefined endomembrane beneath synapse & gp91 phox (Glass et al., 2006; Girouard et al., 2009), p47 phox (Coleman et al., 2013) \\
\hline & Cytosol & gp91 phox (Glass et al., 2006; Coleman et al., 2013) \\
\hline \multirow[t]{2}{*}{ Axons } & The plasma membrane of an axon terminal & gp91 phox (Wang et al., 2015) \\
\hline & Clear vesicles of an axon terminal & gp91 phox (Wang G. et al., 2004; Wang et al., 2015) \\
\hline
\end{tabular}

The most thorough studies used immunogold labeling and immunoperoxidase staining to reveal co-localization of cytb 558 and p47phox in mainly intracellular vesicular organelles, or cell surface in dendrites of the nucleus tractus solitarius (Glass et al., 2006); or localization of p47phox in the paraventricular thalamic nucleus (Coleman et al., 2013).

of them performed by the groups of Iadecola and Wilkens. The immunolocalization is of high quality, and in several cases quantitation of NOX2 subunits distribution was performed (Glass et al., 2006; Coleman et al., 2013). The expression and subcellular distribution of other NOX family members in neurons has not been analyzed in detail.

\section{NOX2 in the Soma of Neurons}

NOX2 can be found at various sites in neuronal cell bodies including the plasmalemma, rough ER, smooth ER, Golgi Complex, mitochondria, multivesicular bodies (MVBs) and vesicles (Wang G. et al., 2004; Girouard et al., 2009; Coleman et al., 2013). However, detection of gp91 $91^{\text {phox }}$ and $\mathrm{p} 22^{\text {phox }}$ at some of these sites is likely due to their biosynthesis.

\section{NOX2 in Neurites}

In developing neurons NOX2 localizes to growth cones, including filopodia and lamella (Munnamalai et al., 2014; Terzi et al., 2021), as we will later discuss. Here, we will mainly focus on mature neurons in vivo, where most ultrastructural studies have been performed. Within dendrites, $\mathrm{p}^{22^{\text {phox }}}, \mathrm{p} 47^{\mathrm{phox}}$, and gp91 $91^{\text {phox }}$ are predominantly found on intracellular vesicular organelles, but also at the plasma membrane close to dendritic spines (Wang G. et al., 2004; Glass et al., 2006; Girouard et al., 2009). In a quantitative study, the majority of NOX2 labeling (gp91 ${ }^{\text {phox }}, \mathrm{p} 22^{\text {phox }}$, and p $^{\text {phox }}$ labeling) was in fact associated with dendrites and less with soma, axons, and terminals (Glass et al., 2006). Intracellularly, $47^{\text {phox }}$ and gp $91^{\text {phox }}$ can be detected in association with vesicular organelles and mitochondria (Glass et al., 2006). Additionally, the gp91 ${ }^{\text {phox }}$ subunit has been found on membranes resembling smooth endoplasmic reticulum (Glass et al., 2006) and in multivesicular bodies (endosomes) (Wang G. et al., 2004).

\section{NOX2 in Synapses}

Two separate studies have used electron microscopy to dissect the subcellular distribution of NOX2 in neurons of the nucleus tractus solitarius (brain stem). One study shows that immunogold-labeled NOX2 is present in pre-synaptic axon terminals, possibly belonging to the vagus nerve. More specifically, NOX2 is found at the plasma membrane and associated with small clear vesicles of the terminal and some MVB's (Wang G. et al., 2004). A different study that systematically quantified the $\mathrm{p} 47^{\text {phox }}$, gp9 $91^{\text {phox }}$, and $\mathrm{p} 22^{\text {phox }}$ distribution concludes that only a fraction of these subunits localize to axon terminals or axons in general (Glass et al., 2006). Both studies, however, agree that $\mathrm{gp} 91^{\text {phox }}, \mathrm{p} 22^{\text {phox }}$, and $\mathrm{p} 47^{\text {phox }}$ can be found on or just beneath the peri-synaptic portions of the post-synaptic (dendritic) plasma membrane (Wang G. et al., 2004; Glass et al., 2006). Interestingly, in a quantitative approach, angiotensin II stimulation was shown to induce $\mathrm{p} 47^{\text {phox }}$ translocation from cytosol to undefined endomembranes in close proximity to post-synaptic membranes of non-vassopressin hypothalamic paraventricular neurons (Coleman et al., 2013). Taken together, NOX2 can be found at synaptic sites, especially in the post-synaptic (dendritic) part, which is also confirmed by biochemical analysis of synaptosome 
preparations (isolated pre- and post-synaptic structures) prepared from hippocampal neurons (Tejada-Simon et al., 2005; Brennan et al., 2009), as well as synaptosome preparations from aged mice (Ali et al., 2011).

\section{NOX AND MUTANT HUNTINGTIN; A DIRECT INTERACTION?}

While there is good evidence for expression of NOX2 in cortical projection neurons (Massaad and Klann, 2011; Nayernia et al., 2014), some of which project to innervate striatal GABAergic MSNs, there are no data on the expression of NOX isoforms in the MSNs themselves. One of the few studies that relates expression of the HD mutation and cellular pathology to NOX expression applied immunoprecipitation which suggests a direct interaction between NOX2 and mutant huntingtin (Bertoni et al., 2011). This study by Bertoni et al. indicated that mutant huntingtin from patient fibroblasts was selectively sequestered in cholesterol- and glycosphingolipidenriched membrane microdomains (lipid rafts) (Bertoni et al., 2011), which are central platforms for organization and signaling. Interestingly, NOX2 also segregates to lipid rafts (Vilhardt and van Deurs, 2004). Moreover, using an inducible polyQ expression system on PC12 cells, they propose that expanded polyQ proteins interact with $\mathrm{gp} 91^{\text {phox }}$, as indicated by coimmunoprecipitation, which promotes NOX2-related oxidative stress in the cells (Bertoni et al., 2011). In accordance with the above, expanded polyQ tracts in Ataxin-7 have been shown to activate NOX in a cell model (Ajayi et al., 2012). Remarkably, treatment of polyQ-GFP-expressing PC12 cells with gp91dsTat (inhibiting NOX2 complex assembly) not only prevented the formation of new polyQ aggregates (which are typical of polyQ expanded diseases such as HD), but also dissolved the already existing ones (Bertoni et al., 2011). Moreover, a single in vivo study shows that instrastriatal injection of quinolinic acid in Wistar rats causes HD like symptoms, as well as increased NOX activity. Inhibition with apocynin resulted in less ROS production and prevented excitotoxicity (Maldonado et al., 2010).

These few studies constitute the entirety of NOX-related research on a HD background, which compared to the wealth of information available on the role of NOX-derived oxidants (mainly from microglia) in other NDDs is surprisingly limited. In the following sections of this review, we will speculate on the possible pathways in HD pathogenesis where NOX could play a role. Therefore, we will look into the known physiological functions of NOXs in neuronal development, differentiation, and synaptic function and plasticity with the purpose of discussing and speculating where in these processes NOXs may be contributing to the pathogenesis of HD. For a wider view of NOX roles in the CNS, we refer to a recent review by Terzi and Suter (2020).

Before we venture into the literature addressing any role of NOX isoforms in neuron function in vivo or in vitro, a technical caveat is warranted. In many studies, various synthetic inhibitors purported to specifically inhibit NOX2 have been used, and the results should be interpreted with caution. For example, apocynin, purported to inhibit $\mathrm{p} 47^{\text {phox }}$ translocation to the membrane, is most likely a general antioxidant and has no specificity for NOX2 (Sorce et al., 2017). Therefore, the use of particularly knockout animal models of NOX isoforms, but also shRNA knockdown or expression of dominant negative constructs of NOX subunits, is the golden standard to affirm specific involvement of any NOX isoform in a given process. The use of gp91 ds-tat is also generally accepted by most as being a specific inhibitor of NOX2. The inhibitor consists of a 9 amino acid peptide of gp91 ${ }^{\text {phox }}$ (amino acids 86-94) which binds to $\mathrm{p} 47^{\mathrm{phox}}$, therefore preventing endogenous complex assembly. The tat portion is a 9 amino acid sequence of the HIV-tat transport region, allowing it to enter into the cells (Rey et al., 2001).

\section{ROLE OF NOXS IN NEUROGENESIS/NEURODEVELOPMENT}

A few studies have delineated a role for NOX2 in neurogenesis in the subventricular zone (SVZ) of the mammal brain, and in human iPSC-derived neurons. Thus maintenance of the neurogenic niche and neuroprogenitor proliferation depends on a sustained oxidant production through NOX2, which is expressed by neurogenic stem cells and their progenitors (Yoneyama et al., 2010; Le Belle et al., 2011; Kokovay et al., 2012; Nayernia et al., 2017). Some details have been unraveled. Thus, vascular cell adhesion protein 1 (VCAM1) expression in neuronal stem cells is essential to uphold the neurogenic niche, and VCAM1 in turn activates NOX2 to produce superoxide (Kokovay et al., 2012). Others have identified upregulation of Akt signaling as important for neuroprogenitor proliferation. NOX2derived oxidants inhibit the opposing phosphatase and tensin homolog (PTEN) (although only chemical NOX2 inhibitors were used to arrive at this conclusion) (Le Belle et al., 2011), and Akt membrane association and activation is itself redox-modulated (Su et al., 2019). The most careful study has been performed using knock-out models to substantiate NOX involvement both in vivo and in vitro during iPSC differentiation to neurons (Nayernia et al., 2017). The authors find that $g p 91^{\text {phox }}$, specifically, is strongly upregulated to allow the passage from pluripotency to neural induction and then disappears during neuronal differentiation and maturation. Interestingly, the downregulation of $\mathrm{p} 22^{\text {phox }}$ is less impressive which could hint at a role for other NOX family members in differentiated cells.

\section{REGULATION OF THE NEUROGENIC STEM CELL NICHE IN HD}

While HD is a neurodegenerative disease, it is also apparent that there is a neurodevelopmental aspect to it, which is played out in iPSC and embryonic stem cell (ESC) models of disease and in animal models. As mentioned earlier, a study using a mouse model conditionally expressing mutant huntingtin (97Q) only until postnatal day 21 showed that many of the 
pathological phenotypes observed in other HD mouse models are recapitulated in the aged mice, indicating that mutant huntingtin expression during development is sufficient for disease induction (Molero et al., 2016). It has been shown that mutant huntingtin expression is associated with a lower rate of progenitor cell division in isogenic ESC models (Ooi et al., 2019), as well as in cortical tissue from HD carrier fetuses at gestation week 13 (Barnat et al., 2020). Moreover, HD neural progenitor cells (NPCs) enter earlier into neuronal lineage fate, in comparison to their WT controls. Studies using mutant huntingtin knockin cell lines showed that NPCs displayed impaired lineage restriction, lower proliferation rates, and aberrant MSN subtype specification (Molero et al., 2016). In unrelated studies by Xu et al. (2017), they corrected the huntingtin mutation in isogenic lines (Control: CAG33, mutant: CAG180) with a CRISPR-Cas9 and piggyBac transposon-based approach. Correction of the mutation reverted the phenotype to proper establishment of neural rosettes in culture, as opposed to what was seen in the non-modified CAG180 line. The latter was a specific effect of the HD mutation given the same genomic background of the isogenic lines (Xu et al., 2017). Given the role of NOX2 in progression from the stem cell niche to neuronal induction (Nayernia et al., 2017), it is possible that derangement of NOX activity could contribute to these phenomena of altered neuronal induction and differentiation in HD.

\section{ROLE OF NOXS IN NEURITE GROWTH, SPECIFICATION, AND CONNECTIVITY DURING DEVELOPMENT AND AFTER NERVE INJURY}

A few in vitro studies first indicated a role for NOX activity in neurite outgrowth and extension in the commonly used catecholaminergic PC12 nerve cell line (Suzukawa et al., 2000; Ibi et al., 2006). But only recently has the involvement of NOX in neurite extension, specification (dendrite or axon), and targeting been addressed in different animal models or in vitro models of nerve cell sprouting (Munnamalai et al., 2014; Olguin-Albuerne and Moran, 2015; Wilson et al., 2015, 2016; Weaver et al., 2018; Terzi and Suter, 2020).

One of the first studies supporting a role of NOX in neurite growth demonstrated the presence of gp91phox in growth cones of Aplysia bag cell neurons. NOX2 was shown to orchestrate actin dynamics in growth cones, since chemical NOX2 inhibition reduced F-actin levels, and lowered retrograde transport, accompanied by shorter neurites (Munnamalai et al., 2014). When neurite growth was induced, an increase in co-localization of $\mathrm{p} 40^{\text {phox }}$ with $\mathrm{gp} 91^{\text {phox }}$ at apCAM (neural cell adhesion molecule (NCAM) homolog) adhesion sites was observed, indicating NOX2 complex formation and activation.

Related studies showed that chemical or genetic inhibition of NOX2 activity significantly diminished neurite outgrowth in primary cerebellar granule neurons (Olguin-Albuerne and Moran, 2015). In vitro peaks of ROS production correlated with high expression and activity of NOX1 and NOX2; also, the majority of hydrogen peroxide production, as measured by the hydrogen peroxide-specific biosensor Hyper, was in focal sites of axonal and dendritic growth cones, as well as in filopodia, with the highest peak before elongation of the latter.

In rat primary hippocampal neurons, NOX2 inhibition by chemical, biological, or genetic (dominant negative $-\mathrm{p} 22^{\mathrm{phox}}$ expression or $\mathrm{p} 47^{\mathrm{phox}(-/-)}$ mice) means, resulted in decreased axonal growth and loss of cell polarization in vitro (Wilson et al., 2015). Expression of dominant negative -p22phox (which would inhibit NOX1-3) also interfered with the lamellae area (region of outgrowth of axons and minor neurites). NOX2 inhibition also reduced the number, length and lifetime of filopodia on axonal tips.

Further studies from the same group using the fluorescent Hyper biosensor (specific for hydrogen peroxide, and amenable for imaging) revealed that the highest hydrogen peroxide production was found at the periphery of the soma as well as at the axonal tip (Wilson et al., 2016). This study also represents the only documented example of a gain-of-function effect (increased neurite growth) when NOX2 activity is increased, in this case by $47^{\text {phox }}$ over-expression. NOX 2 is also present in the growth cones of retinal ganglion cells of zebra fish and is required for proper axonal targeting and connection with the optical tectum (Weaver et al., 2018).

Altogether, the studies suggest a positive role for physiological levels of oxidant production by NOX2 in neuritic outgrowth and arborization in diverse neuronal populations, which may also translate to other neuronal subtypes of the CNS. Interestingly, PC12 cells express both NOX1 and NOX2, which are differentially regulated during NGF-induced differentiation such that NOX2 promotes neurite extension, and is downregulated during the process, while NOX1 opposes neurite extension and is upregulated (Ibi et al., 2006), suggesting different signaling roles depending on the specific NOX isoform. However, the CNS of chronic granulomatous disease (CGD) patients, who lack NOX2 activity, and NOX2 knock-out animal models, develop with only mild cognitive deficits (Kishida et al., 2006). Thus, while a certain redundancy between NOX isoforms can perhaps be expected (Weaver et al., 2018), it seems prudent to conclude that NOX2-mediated redox signaling is a modulating factor, but physiologically important (Terzi et al., 2021), among many, in the development of neurite outgrowth, polarity, targeting, and connections in the brain.

NOX may also have neuroprotective roles. NOX2 activity is required in at least one example of axonal regeneration following peripheral nerve injury. Studies by Hervera and colleagues on mechanically lesioned dorsal root ganglia (DRGs) neurons from mouse, showed that oxidants (hydrogen peroxide) are required for axonal regrowth after nerve injury, indicating a neuroprotective role (Hervera et al., 2018). Unexpectedly, the NOX2 complex is 'delivered' to the DRGs by tissue macrophages by emission of CD63-positive exosomes that contain the full package of NOX2 subunits and are oxidant production proficient. The exosomes are internalized by the DRGs, and traffic to Rab7and Trk-positive signaling endosomes. Interestingly, only those exosomes deriving from WT bone-marrow-derived macrophages (BMDMs), but not Ncf1-/- (human homolog of $\mathrm{p}^{\text {phox }}$ ) or 
Nox2-/- BMDMs, were capable of inducing axonal regrowth after nerve injury (Hervera et al., 2018).

\section{AXONAL PATHFINDING IN HD NEURODEVELOPMENT}

In neurodevelopment axonal pathfinding is crucial to create a proper connectivity in the brain, and here, as is described above, NOX2 has been shown to have a role in growth and neurite guidance of developing neurons, and to localize in growth cones, associated with site specific peaks of ROS production (OlguinAlbuerne and Moran, 2015; Weaver et al., 2018; Terzi et al., 2021). Recent studies have shown that NOX acts as downstream effector of guidance cue molecules in developing neurons, with NOX2 mutants displaying aberrant axonal projections (Terzi et al., 2021). Interestingly, other oxidoreductases may be involved in pathfinding. Members of the cytosolic MICAL (molecule interacting with $\mathrm{CaL}$ ) family of oxidoreductases have been shown to exert an essential function in mediating semaphorin-plexin repulsive axon guidance and cell morphological changes by direct redox modification (cysteine oxidation by hydrogen peroxide) of actin (Hung et al., 2010, 2011). The modification greatly increases affinity of actin for cofilin, an actin-severing protein, and promotes growth cone collapse.

RNAseq analysis of HD iPSCs-derived GABAergic neuronal cultures show a decreased expression of genes that are key for correct axonal guidance (HD IPSCs consortium). Moreover, $\mathrm{Htt}$ is required for newborn neuron migration and for the multipolar to bipolar transition during corticogenesis, as three-dimensional reconstructions of dendritic trees of conditional knockout $\mathrm{Htt}$ cells (timely done when developing neurons have migrated to the different cortical layers targets, and synaptic connectivity needs to be established) resulted in a decrease of the dendritic length and dendritic branching in comparison to control cells (Barnat et al., 2020). Furthermore, in HD human iPSCs derived cortical neurons, longer CAG repeats correlated with shorter neurites. The latter was confirmed by alterations in transcriptomics that corresponded to altered cellular morphology (Mehta et al., 2018). Therefore, it would be interesting to assess if mutant huntingtin changes the pattern of expression and/or activity of NADPH oxidases during neurodevelopment.

\section{NMDAR SIGNALING AND NOX2 ACTIVATION}

Stimulation of N-methyl-D-aspartate (NMDA) glutamate receptors induces oxidant production both physiologically and in relation to excitotoxic cell death (Bindokas et al., 1996; Massaad and Klann, 2011). At first it was surmised that oxidants derived mostly from mitochondria (see discussions in Massaad and Klann (2011), Oswald et al. (2018), Wang and Swanson (2020)), but later it was established that NOX2 is activated subsequent to NMDAR ligation and constitutes the oxidant response (Brennan et al., 2009; Girouard et al., 2009; Brennan-Minnella et al., 2013; Figure 2).

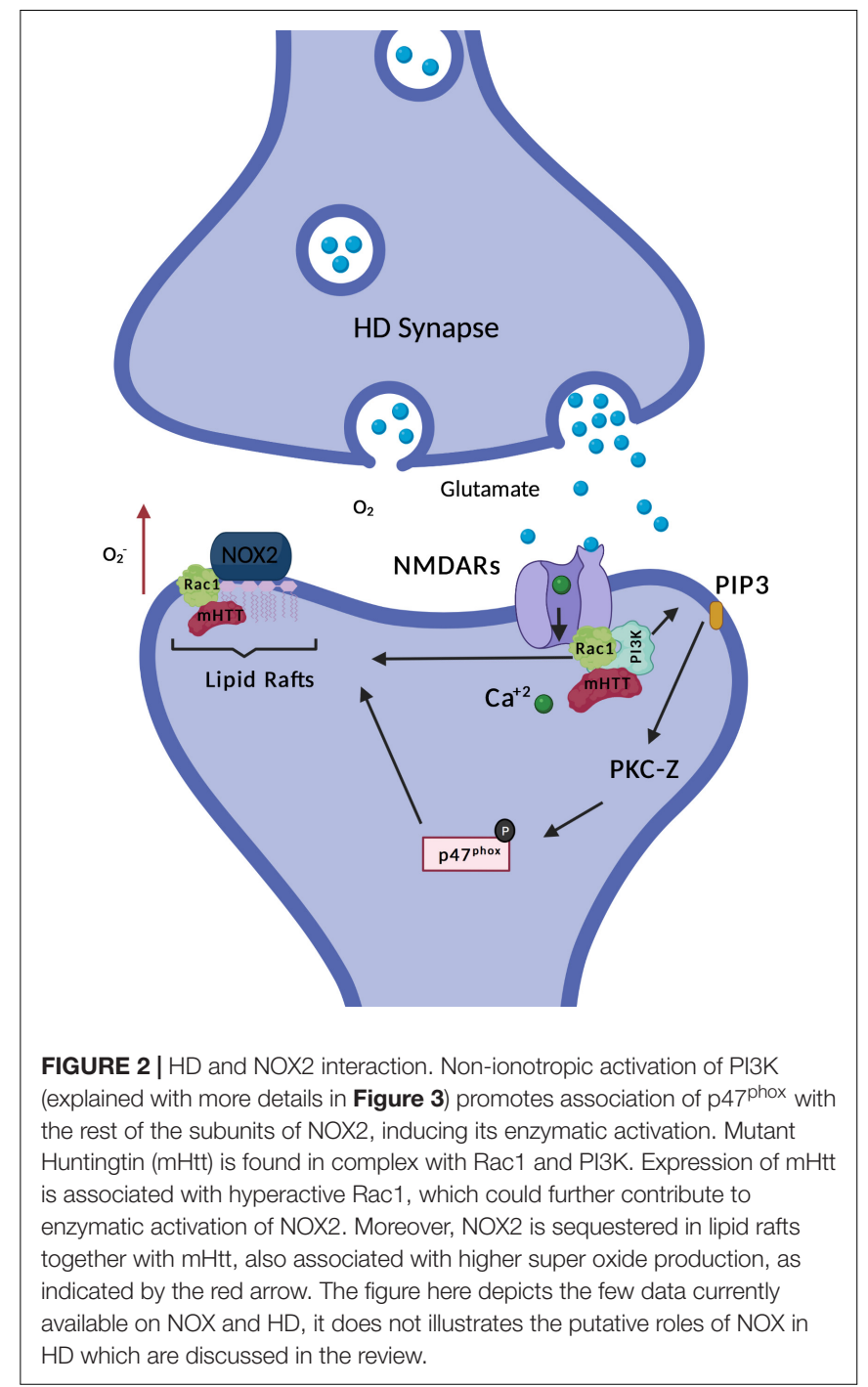

Protein kinase $\mathrm{C}(\mathrm{PKC})$ is an important kinase family that phosphorylates p4 $7^{\text {phox }}$ (Fontayne et al., 2002), which can be activated downstream of NMDAR activation and calcium influx. Early observations, just after the discovery of the expanded NOX family, demonstrated the necessity of both PKC and oxidant production for synaptic potentiation (Knapp and Klann, 2002), and since then, further evidence for the involvement of different PKC isoforms in NOX2 activation following NMDAR stimulation and synaptic plasticity in neurons has been provided (Brennan et al., 2009; Brennan-Minnella et al., 2013; Yi et al., 2018; Wang and Swanson, 2020).

In an in vitro study of mouse cortical neuronal cultures, NMDAR activation-related calcium influx activated PKC-zeta (indirectly, as this novel type PKC does not require calcium for activity) which subsequently phosphorylated $\mathrm{p} 47^{\mathrm{phox}}$ and caused its translocation to the cell membrane for NOX2 activation. When using neuronal cultures from transgenic $\mathrm{p} 47^{\mathrm{phox}-/-}$ mice, as well as when using peptide inhibitors for PKC-zeta, 


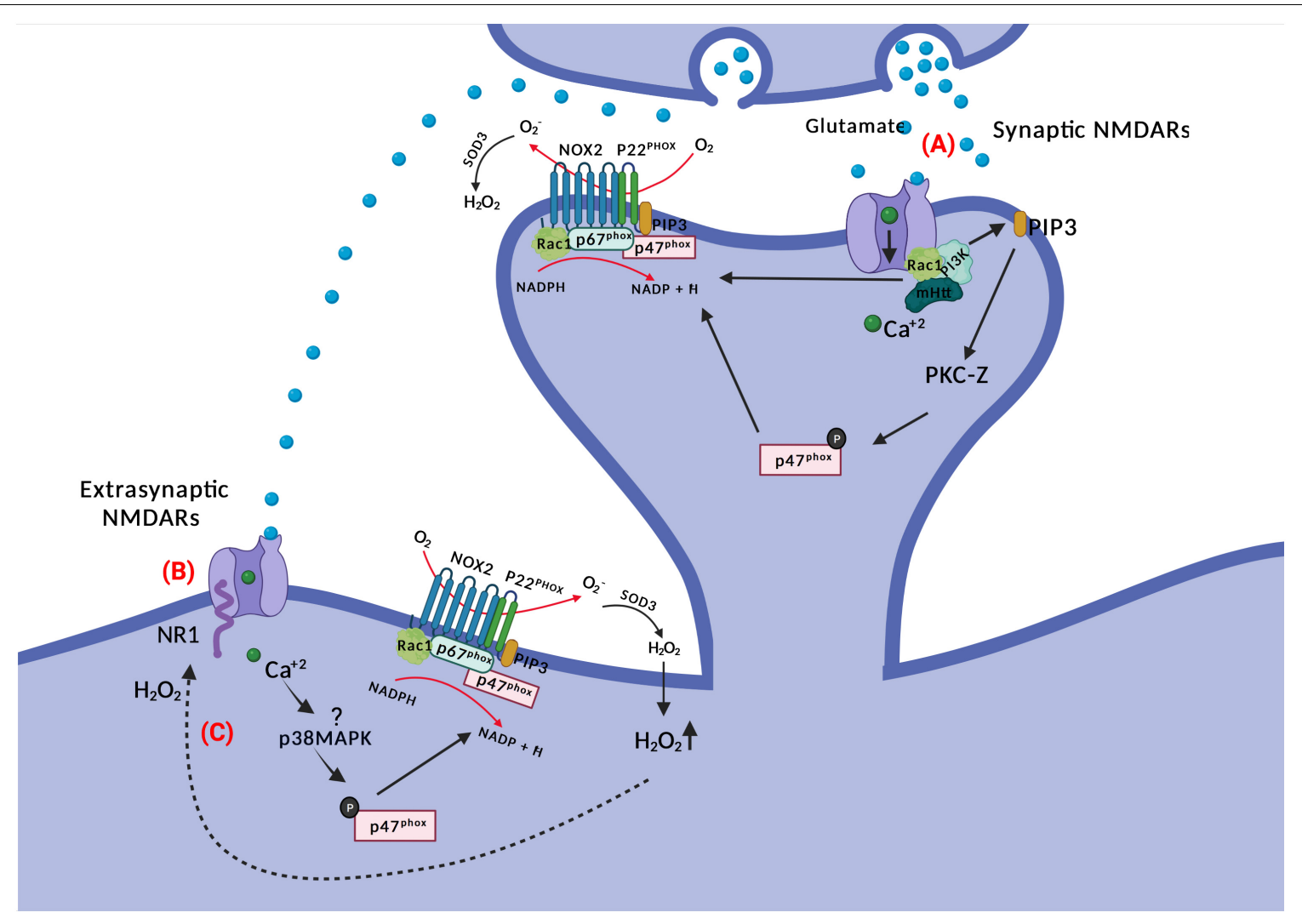

FIGURE 3 | NOX and NMDAR signaling. (A) Glutamate binding to NMDARs activates PI3K non-ionotropically (through conformational changes in the receptor) and subsequent PIP3 production. PIP3 activates PKC-zeta, which phosphorylates p47 ${ }^{\text {phox }}$. The latter translocates to the membrane for NOX2 complex assembly. There is also a requirement for $\mathrm{Ca}^{2+}$ for NMDAR-mediated NOX2 activation; potentially through Rac1. (B) Glutamate spillover can activate extra-synaptic NMDARs, where activated p38MAPK may phosphorylate p47 phox inducing ROS production by NOX2. Extrasynaptic NMDARs activation is associated with neuronal death in HD.

(C) NR1 subunits of NMDARs are redox targets of hydrogen peroxide, which alters their function and conductivity.

oxidant production and excitotoxic cell death was blocked (Brennan et al., 2009).

The evidence for activation of PKC-zeta downstream of NR2B-containing NMDARs is particularly strong (Wang and Swanson, 2020). NR2B-dependent calcium influx through NMDAR leads to activation of phosphoinositide 3-kinase (PI3K) and production of PIP3, the latter activating the atypical PKCzeta, which then phosphorylates $\mathrm{p}^{4} \mathrm{p}^{\text {phox }}$ (Brennan-Minnella et al., 2013). Excitotoxic neuron death and superoxide formation could be prevented by the PI3K inhibitor wortmannin (and p47 $7^{\text {phox }}$ knockout). The involvement of PKC-zeta has been further refined, as it has been demonstrated that specifically phosphorylation at position 316 of $\mathrm{p}^{4} \mathrm{p}^{\mathrm{phox}}$ is required for induction of LTD (Yi et al., 2018). Incidentally, generation of phosphoinositide species in the vesicular or plasma membrane by $\mathrm{PI} 3 \mathrm{~K}$ is also a direct recruitment factor for $\mathrm{p} 40^{\text {phox }}$ and $\mathrm{p} 47^{\mathrm{phox}}$, respectively, via their PX domains (Zhan et al., 2002; Ago et al., 2003; Ellson et al., 2006).

In phagocytes, activation of $\mathrm{p} 47 \mathrm{phox}$ seems dominant in relation to Rac1 activation for NOX2 assembly and enzyme function (Roepstorff et al., 2008), however in artificial systems (Price et al., 2002), and potentially other cell types, Rac1 activation is sufficient to drive NOX2 activation. Tousley and colleagues have contributed with another study possibly linking NOXs and HD, through Rac1 (Tousley et al., 2019b). Racl activity is required for actin remodeling, a process that is required for the change in morphology and structure of dendritic spines. Moreover, actin remodeling is also necessary for the formation of new axonal branches and end-feet, therefore giving it a role in synaptic plasticity and connectivity (Spence and Soderling, 2015). Interestingly, specifically the active form of Rac1 (GTP bound Rac1) is necessary for NOX1, NOX2 and NOX3 enzymatic activation. Huntingtin is found in complex with GTP-Rac1 and p87 $\alpha$ (component of the kinase PI3K) together with alpha-actinin1 and other proteins (Tousley et al., 2019b). This interaction is increased when mutant huntingtin $(\mathrm{mHtt})$ is expressed and is accompanied by Rac1 hyperactivity. In the HD scenario, higher activity of GTP-Racl could be translated to an increased ROS production by Rac1-dependent NOXs (see Figure 2). Increased ROS production by NOXs could further contribute to impaired neuronal arborization dynamics, which in part is coordinated by NOX derived oxidants. The role of NOX derived oxidants in neuronal arborization is explained with more details in 
one of the sections of this review: "Role of NOXs in neurite growth, specification, and connectivity during development and after nerve injury". Remarkably, hyperactivity of Rac1 is associated with dysfunctional neuritogenesis of cortical projection neurons (Zamboni et al., 2018), a neuronal subtype highly affected in HD.

Evidence has been forwarded that the activation of PI3K by NMDAR activation is non-ionotropic, meaning that although $\mathrm{Ca}^{2+}$-conductance is required for NOX2 activation (Wang and Swanson, 2020), PI3K is activated directly by ligand-induced conformational changes in the cytosolic aspect of NMDAR subunits alone (Minnella et al., 2018). This would provide for an exceptionally rapid activation of PKC and NOX2 assembly for oxidant production upon NMDAR ligation by glutamate, in particular if the NOX2 complex is in a primed state and active Rac1 is available.

In an excitotoxic setting, the NMDAR-stimulated oxidant release from neurons is sufficiently robust that it can induce oxidative stress even in neighboring neurons in vitro (Reyes et al., 2012; Brennan-Minnella et al., 2013) and cause their bystander cell death. This may also occur in vivo. Thus, social isolation dramatically upregulates NOX2 in pyramidal neurons of the prefrontal cortex. Nevertheless, it is the small, parvalbuminpositive GABAergic inhibitory interneurons, without NOX2 immunoreactivity, dispersed between the pyramidal neurons that are eventually progressively lost in this psychosocial stress model (Schiavone et al., 2012). When active NOX2 is surface-localized, superoxide, rather than hydrogen peroxide, for an intracellular superoxide source, will be released directly into the surroundings, where it reacts promptly and diffusion-limited with available NO to form the highly toxic peroxynitrite $\left(\mathrm{NO}_{3}{ }^{-}\right)$, which is the main driver of oxidative damage and cell death (Wang and Swanson, 2020). A fraction of ROS is released to the surroundings, and in astrocyte-neuron co-cultures, with neurons coming from E14 mice cortices, it has been shown that NMDAR activation causes oxidative stress in neighboring neurons and glia cells (Reyes et al., 2012). Notably, this does not happen in cultures established from $\mathrm{p} 47^{\mathrm{phox}-/-}$ neurons, indicating the crucial role of NOX2 in the matter (Reyes et al., 2012).

Whether NMDA promotes NOX2 activation also extrasynaptically is not settled. A single study has linked NR2B (a subunit of the NMDAR receptors which is enriched in extrasynaptic sites and associated with cell death (Hardingham, 2009; Martel et al., 2009)) with superoxide production. Treatment of neuronal cultures with $\mathrm{N} 2 \mathrm{RB}$ antagonists resulted in blockage of NMDAR-induced NOX2 superoxide production and excitotoxic cell death (Brennan-Minnella et al., 2013), indicating a crosslink between NOX and excitotoxic neuronal cell death. But interestingly, the authors showed that after blocking specifically synaptic NMDARs with MK801, activation of the remaining (extrasynaptic) NMDARs with bicuculline and 4-aminopyridine still provoked an increase in dihydroethidium (DHE) fluorescence, suggesting that extrasynaptic NMDARs can also activate oxidant generation. Moreover, adding NADPH into the bath triggered a rise in DHE fluorescence which was higher than without synaptic receptors blockage (Brennan et al., 2009), implicating NOX activity rather than mitochondria as the oxidant source. Extrasynaptic NMDAR signaling upregulates the activity of $\mathrm{p} 38 \mathrm{MAPK}$, and this stress kinase is known to phosphorylate and partially activate (prime) $\mathrm{p} 47^{\text {phox }}$ and NOX2 (Brown et al., 2004; Dang et al., 2006).

\section{NMDAR EXCITOTOXICITY IN HD}

Excitotoxic cell death, caused by overactivation of NMDA receptors, has been considered in the pathogenesis of $\mathrm{HD}$, and specifically extrasynaptic NMDAR are associated with striatal neuronal loss in HD (Heng et al., 2009). Synaptic versus extrasynaptic NMDAR signaling, or hypofunction of NMDAR, already causes a reduced balance of transcription of antioxidant genes (Hardingham and Bading, 2010; Hardingham and Do, 2016). Intriguingly, the signaling processes that emanate from synaptic versus extrasynaptic NMDARs are radically different. Thus, glutamate stimulation of synaptic NMDAR initiates pro-survival pathways including the PI3K-Akt pathway and ERK signaling, suppresses death gene transcription, and stimulates transcription of antioxidant genes and CREBdependent transcription (Hardingham and Bading, 2010). In contrast, extrasynaptic NMDAR stimulation leads to activation of p38MAPK and FOXO1 transcription factor activation, which in effect oppose the signaling pathways and transcription imposed by synaptic NMDAR signaling, including a lessened transcription of antioxidant genes. The end result is a disruption of prosurvival pathways and an altered redox balance (Hardingham and Bading, 2010; Szlachcic et al., 2015; Hardingham and Do, 2016). The situation is exacerbated by the inhibition of peroxisome proliferator-activated receptor gamma coactivator 1-alpha (PGC$1 \alpha$ ) function by mutant huntingtin. Normally, PGC- $1 \alpha$ directs the transcription of several antioxidant genes (St-Pierre et al., 2006), and regulates the flow of electrons through the respiratory chain in mitochondria, but through a direct interaction mutant huntingtin inhibits PGC- $1 \alpha$-assisted transcription (Cui et al., 2006; Weydt et al., 2006). Thus, in the HD brain the stage is set for any subsequent overproduction or unwarranted production of oxidants in time and space - e.g., from NOX activation to do damage.

\section{NOX AND OXIDANTS IN THE PRE-SYNAPTIC COMPARTMENT}

NOX-derived oxidants could play a role pre-synaptically by producing oxidants in close proximity to the protein machinery responsible for neurotransmission. Alternatively, oxidants produced in the post-synapse may trans-synaptically modulate pre-synaptic mechanisms such as glutamate release. Such a role is already documented for NO (Stanton et al., 2003) and is a form of synaptic plasticity. The SNARE complex is necessary for docking and fusion of the synaptic vesicles into the pre-synaptic membrane in active synapses. Interestingly, it has been shown that SNAP25, one of the components of the core SNARE complex, is specifically sensitive to oxidation by hydrogen peroxide, and that pre-exposure to $100 \mu \mathrm{M}$ levels 
of hydrogen peroxide is sufficient to prevent SNARE complex assembly. Oxidants could be supplied by NOX2 in the presynapse itself or extrinsically by either activated microglia or post-synaptic NOX2 activity. In the latter case, oxidants would modulate pre-synaptic function across the synaptic cleft similar to other short-lived metabolites such as NO or endocannabinoids (Gerdeman et al., 2002; Stanton et al., 2003). Furthermore, protein levels of specifically SNAP25 in the pre-synaptic plasma membrane are reduced in neurons that are subjected to oxidative stress and SNAP25 knockout experiments in non-diseased cortical projection neurons (CPNs) has been shown to induce neurodegeneration (Hoerder-Suabedissen et al., 2019). Deficits in SNAP25 expression and function has been reported in HD (Smith et al., 2007). Therefore, deficits in the SNAREs machinery function of HD synapses, as a result of exposure to NOX-derived ROS, could be a potential contributor to the synaptopathology of the disease.

\section{NOX INVOLVEMENT IN LONG-TERM DEPRESSION/POTENTIATION AND SYNAPTIC PLASTICITY}

Synaptic plasticity is in part orchestrated by long-term potentiation (LTP) and long-term depression (LTD) (Figure 4). LTP is a persistent rise in synaptic strength following highfrequency stimulation of a synapse. On the other hand, LTD is an activity-dependent decrease in the strength of synaptic connectivity. Both processes play a crucial role in the formation of specific types of memories and learning (Massaad and Klann, 2011). For example, recognition memory (the capacity to recognize formerly encountered events, objects or individuals) is processed through LTD by neural circuits in the perirhinal cortex, specifically, through an activity-dependent decrease in the efficacy of neurotransmission at glutamatergic synapses. Even though LTP and LTD effect on synaptic excitability are opposite, they can both happen at the same synapse in response to different patterns of activation of NMDARs combined with membrane depolarization. Typically, the final outcome is in one way or the other a modulation of the number and functionality of $\mathrm{Na}^{+}$conducting $\alpha$-amino-3-hydroxy-5-methyl-4-isoxazolepropionic acid (AMPA) receptors in the post-synaptic membrane, but other mechanisms exist (Collingridge et al., 2010).

In relation to NOX2, it was first shown that hippocampal plasticity and LTP was impaired in mouse models of CGD with no gp91 $1^{\text {phox }}$ or $\mathrm{p} 47^{\text {phox }}$ expression (Kishida et al., 2006). Studies have since then shown that oxidants and NOX2 are essential for LTP induction (see Massaad and Klann (2011) for a good historical review).

LTP can be blocked by the use of different oxidant scavengers (Lee et al., 2010), including mouse models with overexpression of extracellular SOD3 (Thiels et al., 2000), and conversely, LTP can be induced by application of xanthine/xanthine oxidase (a superoxide source) to the extracellular medium of hippocampal brain slices (Knapp and Klann, 2002). However, the latter is clearly context-dependent, as NOX2-derived oxidants from inflammatory microglia can in fact inhibit LTP induction
(Wang Q. et al., 2004; Di Filippo et al., 2016). Presumably the outcome is modulated by additional reciprocal interactions between microglia and neurons (Hanisch and Kettenmann, 2007; Kettenmann et al., 2013), and it should also be noted that the effect of hydrogen peroxide concentration on LTP induction is bimodal (Kamsler and Segal, 2003).

Most studies have found that NOX2 expression in the spinal cord lies with either microglia or macrophages, where its activity plays a role in altered pain perception (Kallenborn-Gerhardt et al., 2013, 2014; Lim et al., 2013). Others have found that DRG expression of NOX4 is required for maintenance of the late phase of neuropathic pain after peripheral neurons injury, and conditional deletion of NOX4 in adult mice reduced painrelated behavior (Kallenborn-Gerhardt et al., 2012). However, one recent study proposes that LTP induction by high frequency train stimulation of the sciatic nerve in the dorsal spinal cord depends on NOX2 expression in neurons, and further describes upregulation of gp91 ${ }^{\text {phox }}$ (Xu et al., 2020). LTP induction, but not maintenance, could be inhibited by gp91ds-tat, and further, gp91 ${ }^{\text {phox }}$ knock-down inhibited allodynia in this mouse model of pain perception.

Post-synaptic NOX2 activity is also required for NMDARdependent LTD (Yi et al., 2018). LTD induced by low frequency stimulation on acute neuronal slices was dependent on postsynaptic expression of NOX2 as verified by shRNA knockdown of gp91 $1^{\text {phox }}$ and $\mathrm{p} 47^{\text {phox }}$. They also demonstrated that $\mathrm{p} 47^{\text {phox }}$ phosphorylation at serine 316 by $\mathrm{PKC}$-zeta is specifically required for LTD induction.

In some cases, oxidants do not have to be produced by neurons themselves to affect synapse function. In a pathological setting, $\mathrm{A} \beta$ provokes superoxide production by microglia through NOX2, and this accounts for the $A \beta$-induced inhibition of LTP in brain slices from mice (Wang Q. et al., 2004), and similarly, in the remitting phase of an experimental multiple sclerosis model, hippocampal LTP is impaired because of microglial NOX2 activity (Di Filippo et al., 2016). It has later been shown in an experimental LTD paradigm of combined hypoxia/LPSstimulation in mouse models, that microglia through LPS activation of complement receptor 3 (CR3) within minutes activates NOX2 to release superoxide, which initiates a signaling cascade in the post-synapse of hippocampal neurons to downregulate AMPA glutamate receptors, a known mechanism of LTD and synapse weakening (Zhang et al., 2014).

The opposing actions of oxidants on plasticity, dependent on context and oxidant concentration, and similarly, the participation of NOX2-derived oxidants in both LTP and LTD induction, can seem contradictory and puzzling, and clearly calls for more research into the area. A part of a reconciliatory explanation may reside in the precise subcellular localization of the oxidant source, and the differing membrane permeabilities of superoxide versus hydrogen peroxide.

In the redox signaling business proximity of oxidant producer and redox target is essential for redox modification, because the penetration range of hydrogen peroxide in cytosol is on the border of only 1-2 $\mu \mathrm{m}$ before extinction by the cellular antioxidant machinery (Winterbourn, 2008; Jones and Sies, 2015). It follows, that if two redox signaling circuits, with 


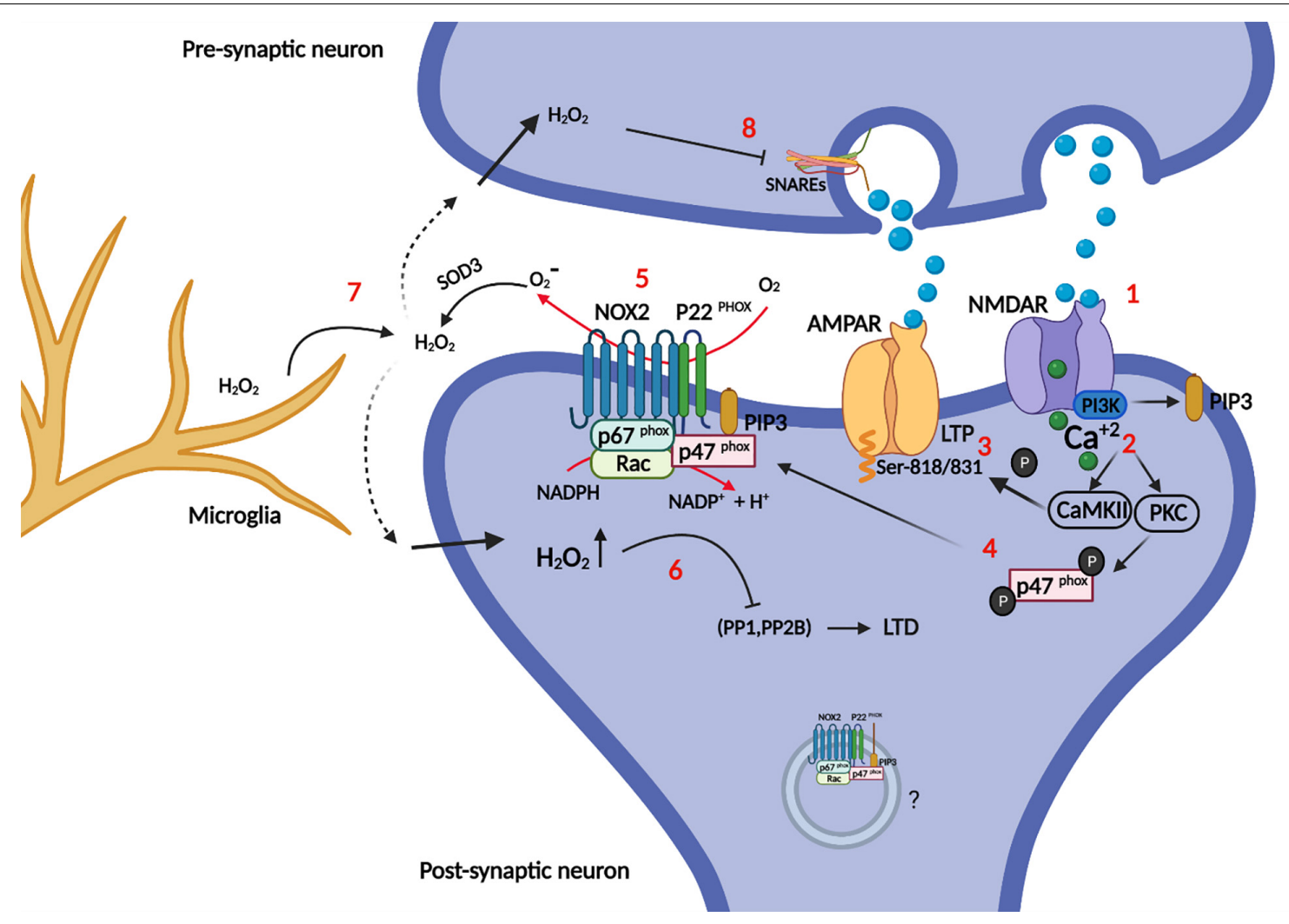

FIGURE 4 | Role of NOX in synapse plasticity. Briefly, synaptic plasticity is governed mainly by LTP: Synapse enhancement through recruitment of AMPA receptors into the post-synaptic membrane and LTD: synapse weakening (AMPA receptors endocytosis). (1) Glutamate binding to NMDARs opens the calcium channel, and activates PI3K directly. (2) Calcium activates CaMKII and PKC (the latter also requires PIP3 as explained in Figure 2), which can both (3) phosphorylate AMPARs at specific serines, increasing their conductance and recruitment into the post-synaptic membrane (LTP). Moreover (4) p47 phox is phosphorylated by PKC, which recruits it for complex assembly and activation of NOX2. (5) Enzymatically active NOX2 produces superoxide in the extracellular space, which is cycled back into the cytosol as hydrogen peroxide after dismutation by SOD3. (6) Intracellular hydrogen peroxide potentially redox-regulates phosphatases PP1, and PP2B by oxidation. These phosphatases dephosphorylate AMPARs, promoting their endocytosis and removal from the post-synaptic membrane (LTD). The intra-synaptic pool (depicted inside a vesicle) of NOX2 may be activated differentially from the perisynaptic NOX2 in the plasma membrane and could represent a layer of specificity to redox signaling. (7) NOX2 derived oxidants from microglia may impair instillation of LTP or conversely promote LTD. (8) Hydrogen peroxide can also enter the presynaptic neuron and impair the SNAREs machinery, which is required for synaptic vesicle release.

different outcomes, are to arise from the same oxidant source either different redox targets must be recruited dynamically to the immediate vicinity of a fixed oxidant source, or physically separated pools of oxidant producer affects different redox targets. It is therefore intriguing, that NOX2 in post-synapses is also located to endosomal elements and small unidentified vesicles and membranes (Coleman et al., 2013) in addition to the peri-synaptic surface membrane (Wang G. et al., 2004; Glass et al., 2006). Further, NOX 2 activation can be directed spatially, and the proximal assembly of the holoenzyme adapted to the stimuli for activation. For example, p40 phox is specifically required for IgG-FcgR induced activation of NOX2 in phagocytes, where it assists the function of $4^{7^{\text {phox }}}$ as organizer of NOX2 assembly (Anderson et al., 2011; Ueyama et al., 2011). In addition, because of differing affinities for phosphoinositide species, $\mathrm{p} 40^{\text {phox }}$ is recruited mainly to intracellular vesicles, whereas $\mathrm{p} 47^{\text {phox }}$ associates with the plasma membrane (Zhan et al., 2002). In phagocytes, there is good evidence for the differential activation of cell surface resident versus intracellular pools of NOX2 (Serrander et al., 1999; Li et al., 2010), and potentially similar mechanisms could be at work in the postsynapse.

However, the penetration range of hydrogen peroxide exceeds with a good measure the size of most synapses, which speaks against a resolution of LTD/LTP-associated differential redox signaling based on physical distance alone. Another, independent or reinforcing, speculative mechanism therefore lies in the different membrane permeabilities of superoxide (charged and impermeable) and hydrogen peroxide (fairly permeable). It is curious that extracellular SOD3 abolishes LTP induction (Thiels et al., 2000), even though the enzyme converts superoxide into hydrogen peroxide, the generally accepted relayer of redox signals (Winterbourn, 2013; Sies and Jones, 2020). Could it be that specificity for one form of plasticity over the other could in part be achieved by cell surface-resident NOX2 and superoxide-mediated oxidation of cell surface proteins on the extracellular aspect? Being membrane-impenetrable, superoxide action would be restricted to redox targets on the surface 
in the immediate vicinity of NOX2, further reinforced by the quick dismutation to hydrogen peroxide. Only a few examples of superoxide in redox signaling are known however (Sies and Jones, 2020), and the proposed mechanism breaks with the current dogmatic view of cell surface receptorinduced NOX activation, which relies on back-diffusion of hydrogen peroxide through the membrane directly or through aquaporins to modulate intracellular redox targets. It is unknown whether synapses express aquaporins (which allows hydrogen peroxide to move along its concentration gradient), and to what extent vesicular NOX2 in synapses contributes to oxidant production, but endosomal NOX2-mediated oxidant production has been proposed in other cell types (Oakley et al., 2009; Lamb et al., 2012), and NOX2 storage vesicles also have oxidant production capability (Moreland et al., 2007; Ejlerskov et al., 2012).

The redox targets of NOX2 in synapses are entirely unknown. However, a major function of NOX2 is to regulate, by oxidative inactivation, the activity of both tyrosine and serine/threonine phosphatases (Sies, 2014). LTD and LTP are governed by a balance of kinases like PKC and $\mathrm{Ca}^{2+}$-calmodulin-dependent protein kinase II (CaMKII) (promotes LTP), and opposing phosphatases calcineurin (PP2B), PP1 and PP2A (promotes LTD) (Collingridge et al., 2010). Phosphorylation of AMPA receptors increases conductance and their synaptic incorporation during LTP, while dephosphorylation promotes their endocytosis, and LTD and synapse weakening. Interestingly, calcineurin, PP1A, and PP2A are all inactivated by hydrogen peroxide (Rhee et al., 2000). and NOX2 derived oxidants could activate PKC (in a feedback loop) (Knapp and Klann, 2002), and similarly, Akt, which also phosphorylates and activates $47^{\text {phox }}$ (Hoyal et al., 2003), is in part positively regulated by redox modification (Luo et al., 2012) (Su et al., 2019). Finally, NMDARs are targets for redox modification themselves. Redox modifications of cysteine residues in the cytosolic tails of particularly NR1B modulate NMDAR function (Lipton et al., 2002), and there is evidence that NOX2 contributes to this process (Di Maio et al., 2011). Interestingly, evidence for NOX2derived oxidant alteration of the stoichiometric composition of the NMDAR (upregulation of NR2B) has been presented following cholinergic stimulation of $\mathrm{m} 1 \mathrm{R}$ metabotropic receptors (Di Maio et al., 2011). In addition, metabotropic receptors can be redox modified (Campanucci et al., 2008; Coddou et al., 2009).

Outside of synapses it has been shown that NOX2 activity is required for axonal development by causing $\mathrm{Ca}^{2+}$ release from endoplasmatic reticulum through Ryanodine receptors (Wilson et al., 2016). However, it was not investigated whether the ryanodine receptor was a direct target of redox modification, as observed in other cell types where evidence of NOX4 participation is particularly strong (Sun et al., 2011). Notably, store operated calcium entry is affected in HD (Czeredys, 2020) likely downstream of an interaction between $\mathrm{mHtt}$ and the IP3R1 receptor in the rER, which sensitizes the IP3R calcium channel, such that calcium in rER is depleted and subsequently activates the store operated entry of calcium (Wu et al., 2016).

\section{NOX2, LTD/LTP AND HD PATHOLOGY}

The memory deficits that are characteristic of HD, and demonstrated in patients as well as mouse models, include failure in recognition memory (Giralt et al., 2011), and cognitive dysfunction (Milnerwood et al., 2006) which are manifest early in the disease (Montoya et al., 2006).

Electrophysiological measurements in brain slices from several different genetic mouse models have consistently shown LTP dysfunction in $\mathrm{HD}$, not only the most commonly characterized hippocampal LTP (Hodgson et al., 1999; Usdin et al., 1999; Murphy et al., 2000; Quirion and Parsons, 2019) but also in the cortico-striatal synapse (Kung et al., 2007; Dallérac et al., 2011; Plotkin et al., 2014; Sepers et al., 2018). The effect of mutant huntingtin on the ability to evoke stimulation-induced LTD, also studied in various HD mouse models, is less clear. LTD evocation has been shown to be diminished in the perirhinal cortex in the R6/1 mouse model (Cummings et al., 2007) and in cortico-striatal synapses (Ghiglieri et al., 2019; Kim et al., 2020), but reports of similar changes in hippocampus has not been consistent (Murphy et al., 2000; Milnerwood and Raymond, 2007; Ghilan et al., 2014).

Different mechanisms have been proposed to convey these effects, including changes in dopamine receptor function and endocannabinoid receptor activity (Sepers et al., 2018; Ghiglieri et al., 2019). Dopamine D1 receptor activity has been shown to regulate the expression and activity of NMDAR, which as described above is essential for LTP and LTD; as D1 receptor hypersensitivity has been shown in HD this presents a potential mechanism for the involvement of mutant huntingtin in synaptic plasticity (Ghiglieri et al., 2019). Another potential mechanism involves the "alternative" brain-derived neurotrophic factor (BDNF) receptor $\mathrm{p} 75^{\mathrm{NRT}}$ : BDNF exerts neurotrophic actions and stimulates LTP and LTD through activation of the TrkB receptors, however, $\mathrm{BDNF}$ binding to $\mathrm{p} 75^{\mathrm{NRT}}$ has been proposed to have antagonistic effects on synaptic plasticity (Brito et al., 2014). Interestingly, increased protein levels of $\mathrm{p} 75^{\mathrm{NRT}}$ has been shown in HD patients and mouse models (Brito et al., 2014), and in cortico-striatal synapses HD-associated abnormalities in LTP were restored by inhibiting p75 ${ }^{\mathrm{NRT}}$ (Plotkin et al., 2014). p75 ${ }^{\mathrm{NRT}}$ activation acts through PTEN, which, as described previous in this review, may be inhibited by NOX-derived ROS (Le Belle et al., 2011).

\section{MICROGLIA AND NOX2 IN HD}

Glial cells might be contributors to the pathology of HD (Wilton and Stevens, 2020), and when it concerns NADPH oxidases, by far, the most literature on NOX2 in the brain involves microglia, the resident CNS phagocytes, which additionally express NOX1 (Cheret et al., 2008). As phagocytes, they are equipped for high level oxidant production following pathogen encounter, and the very same pattern of recognition receptors come into play in the recognition of extracellular amyloids (Fellner et al., 2012; Qiao et al., 2015; Wang et al., 2015). 
Relative to the common neurodegenerative diseases like Alzheimer's (AD) and Parkinson's disease (PD), the mass of literature on microglia in $\mathrm{HD}$ is limited. Search terms 'AD/PD/HD' AND 'microglia' retrieves 5755, 2600, and 257 records from PubMed, respectively. The information on NOX2 activity in microglia of animal models of HD is virtually nonexistent and has only been addressed peripherally in vitro.

This despite the fact that PET scanning of HD patients with peripheral benzodiazepine receptor ligands (11C-(R)-PK11195), as measure of microglia activation, indicates that microglia are activated well before clinical disease onset (Pavese et al., 2006; Tai et al., 2007). Post mortem HD brains show typical signs of neuroinflammation including cytokine production and complement deposition (Singhrao et al., 1999) as well as markers of oxidative stress (see references in Bono-Yagüe et al. (2020)).

Transcriptional profiling of $\mathrm{AD}$ brain shows a clear inflammatory signature (Block et al., 2007) (Malik et al., 2015), and a significant correlation between NOX activity and cognitive decline exists (Ansari and Scheff, 2011). In PD models, dopaminergic neuron death can be instilled by the mere stereotactic infusion of LPS into the substantia nigra to activate microglia and NOX2 specifically (Qin et al., 2004).

The situation is somewhat different in animal models of $\mathrm{HD}$, where microglia activation and neuroinflammation seems more subdued. While microglia in early disease in the R6/2 HD model decrease ramification and assume more activated shapes, indicating that microglia are detecting (Kraft et al., 2012) and responding to a deviation from homeostasis, possibly derangement of synaptic function (Milnerwood and Raymond, 2007), a neuroinflammatory profile with full blown microglia activation and proinflammatory cytokine production is observed only late in the disease (see Wilton and Stevens (2020) for an overview). At this point microglia activation is not necessarily disease-specific but represents a prototypical response to neuronal death processes, particularly so in the R6/2 mouse model where the course of disease is very aggressive (mice die at 16 weeks of age). Therefore, the recent demonstration that shRNA knock-down of Galectin 3 in R6/2 mice dampens microglia activation, neuroinflammatory profile, and ameliorates disease (increasing survival) is surprising (Siew et al., 2019). It will be interesting to see whether microglia activation also plays out as a driver of pathology in other HD animal models with a more protracted disease course than R6/2 mice (Plotkin and Surmeier, 2015).

In contrast to idiopathic brain disease, where microglia are typically initially activated down-stream of neuronal dysfunction or extracellular amyloid aggregates, all glia cells in $\mathrm{HD}$ endogenously express mutant huntingtin, which affects their activation and function from within (Wilton and Stevens, 2020). In the R6/2 model, microglia display pro-inflammatory transcriptional activation by increasing the expression and transcriptional activities of the myeloid lineage-determining factors PU.1 and C/EBPs (Crotti et al., 2014). Of note, increased transcription of PU.1 and C/EBP target genes was microglia specific in the R6/2 model, which contrasts with the monocytic priming by mutant huntingtin expression observed early in human patients (Bjorkqvist et al., 2008). It has also been noted that microglia, and myeloid cells in general, in experimental HD models or patients show a reduced migratory response versus chemotactic stimuli in vitro or laser-induced injury in vivo (Kwan et al., 2012). However, selective depletion of mutant huntingtin in myeloid cells, including microglia, has no bearing on disease development in the BACHD HD mouse model (Petkau et al., 2019).

Whereas both amyloid- $\beta$ (Bianca et al., 1999; Zhang et al., 2011) and $\alpha$-synuclein (Fellner et al., 2012; Qiao et al., 2015; Wang et al., 2015) aggregates induce NOX2-dependent superoxide production in microglia through specific scavenger receptors, no such data are available for mutant huntingtin aggregates. In fact, no internalization or signaling cell surface receptors are known for mutant huntingtin in microglia (or in any other cell type for that matter). To date therefore, no publications have specifically addressed microglial NOXmediated oxidant production in an in vitro or in vivo setting of HD models, discounting studies that, too optimistically, rely only on apocynin or other general anti-oxidant inhibition as measure of NOX involvement (Maldonado et al., 2010; O’Regan et al., 2021).

\section{CONCLUSION}

While the role of microglia and NOX2-mediated oxidant production in the progression of late stage neurodegenerative disease is undisputed, the involvement of neuronal NOX isoforms in physiology and brain pathology are just in the process of being unraveled. From the early recognition of a requirement for superoxide for LTD/LTP instigation, several groups have now contributed to the delineation of the pathways that lead to NOX2 activation following NMDAR engagement in synaptic parts of neurons. However, the redox circuits downstream of NOX2 oxidant production, and in particular how both LTD and LTP are redox controlled by NOX2, awaits further elucidation, and presumably identification of protein redox targets. It will also be interesting to see whether the deleterious effects of extrasynaptic NMDAR signaling are mediated in part by NOX2 activity and by which pathway; if different from synaptic NOX2 activation they could perhaps be uncoupled pharmacologically.

Any specific effects of neuronal NOX activity in HD would depend in the (1) stage of the disease, (2) specific cell type and NOX isoform involved, and (3) subcellular localization of the enzyme - the latter given the complex neuronal morphology and extensive length of the axons, allowing for several redox signaling microcircuits to occur within the same cell. And last but not least, (4) NOX-derived ROS from other cell types, in this particular case microglia, may also play a role in HD disease progression, which has not been fully explored yet.

We have presented evidence that NOX function could potentially participate from the very start of developmental defects seen in HD, including altered neurogenesis, neurite growth, and axonal pathfinding, while also having a possible role in mature neurons where NOX2 regulates NMDAR signaling and synaptic plasticity, known to be affected in presymptomatic 
HD. It will be essential to follow up on the present isolated findings of mHtt modulation of PI3K and Racl signaling, as it will be important to establish whether $\mathrm{mHtt}$ interacts with NOX2 in lipid raft compartments of the membrane to interfere with crucial synaptic processes that mediate synaptic plasticity and maintenance. To the extent that the "dying back" pattern of degeneration in which loss of synaptic connectivity and axonal degeneration precedes and provokes neuronal death over time (Han et al., 2010), a lot could potentially be gained by remedying initial synaptic dysfunction in the striatum, which would also presumably ameliorate early motor symptoms.

\section{REFERENCES}

Ago, T., Kuribayashi, F., Hiroaki, H., Takeya, R., Ito, T., Kohda, D., et al. (2003). Phosphorylation of $\mathrm{p} 47$ phox directs phox homology domain from SH3 domain toward phosphoinositides, leading to phagocyte NADPH oxidase activation. Proc. Natl. Acad. Sci. U.S.A. 100, 4474-4479. doi: 10.1073/pnas.073571 2100

Ajayi, A., Yu, X., Lindberg, S., Langel, U., and Ström, A. L. (2012). Expanded ataxin7 cause toxicity by inducing ROS production from NADPH oxidase complexes in a stable inducible Spinocerebellar ataxia type 7 (SCA7) model. BMC Neurosci. 13:86. doi: 10.1186/1471-2202-13-86

Ali, S. S., Young, J. W., Wallace, C. K., Gresack, J., Jeste, D. V., Geyer, M. A., et al. (2011). Initial evidence linking synaptic superoxide production with poor shortterm memory in aged mice. Brain Res. 1368, 65-70. doi: 10.1016/j.brainres. 2010.11.009

Anderson, K. E., Chessa, T. A., Davidson, K., Henderson, R. B., Walker, S., Tolmachova, T., et al. (2011). PtdIns3P and Rac direct the assembly of the NADPH oxidase on a novel, pre-phagosomal compartment during FcRmediated phagocytosis in primary mouse neutrophils. Blood 116, 4978-4989. doi: 10.1182/blood-2010-03-275602

Ansari, M. A., and Scheff, S. W. (2011). NADPH-oxidase activation and cognition in Alzheimer disease progression. Free Radic. Biol. Med. 51, 171-178. doi: 10.1016/j.freeradbiomed.2011.03.025

Banfi, B., Tirone, F., Durussel, I., Knisz, J., Moskwa, P., Molnar, G. Z., et al. (2004). Mechanism of Ca2+ activation of the NADPH oxidase 5 (NOX5). J. Biol. Chem. 279, 18583-18591. doi: 10.1074/jbc.M310268200

Barnat, M., Capizzi, M., Aparicio, E., Boluda, S., Wennagel, D., Kacher, R., et al. (2020). Huntington's disease alters human neurodevelopment. Science 369, 787-793. doi: 10.1126/science.aax3338

Bates, G. P., Dorsey, R., Gusella, J. F., Hayden, M. R., Kay, C., Leavitt, B. R., et al. (2015). Huntington disease. Nat. Rev. Dis. Primers 1:15005. doi: 10.1038/nrdp. 2015.5

Bauerlein, F. J. B., Saha, I., Mishra, A., Kalemanov, M., Martinez-Sanchez, A., Klein, R., et al. (2017). In situ architecture and cellular interactions of PolyQ inclusions. Cell 171, 179-187.e10. doi: 10.1016/j.cell.2017.08.009

Bedard, K., and Krause, K. H. (2007). The NOX family of ROS-generating NADPH oxidases: physiology and pathophysiology. Physiol. Rev. 87, 245-313. doi: 10. 1152/physrev.00044.2005

Bell, K. F., Al-Mubarak, B., Martel, M. A., McKay, S., Wheelan, N., Hasel, P., et al. (2015). Neuronal development is promoted by weakened intrinsic antioxidant defences due to epigenetic repression of Nrf2. Nat. Commun. 6:7066. doi: 10.1038/ncomms8066

Bertoni, A., Giuliano, P., Galgani, M., Rotoli, D., Ulianich, L., Adornetto, A., et al. (2011). Early and late events induced by polyQ-expanded proteins: identification of a common pathogenic property of polYQ-expanded proteins. J. Biol. Chem. 286, 4727-4741. doi: 10.1074/jbc.M110.156521

Bianca, V. D., Dusi, S., Bianchini, E., Dal Pra, I., and Rossi, F. (1999). betaamyloid activates the O-2 forming NADPH oxidase in microglia, monocytes, and neutrophils. A possible inflammatory mechanism of neuronal damage in Alzheimer's disease. J. Biol. Chem. 274, 15493-15499. doi: 10.1074/jbc.274.22. 15493
We hope that it can be conjectured from the present review that the relative 'under-representation' of literature on NOX in HD compared to other NDDs cannot simply be explained by the different prevalence of these diseases; there is certainly room for future research into the roles of NOX and oxidants in HD.

\section{AUTHOR CONTRIBUTIONS}

All authors listed have made a substantial, direct and intellectual contribution to the work, and approved it for publication.

Bindokas, V. P., Jordán, J., Lee, C. C., and Miller, R. J. (1996). Superoxide production in rat hippocampal neurons: selective imaging with hydroethidine. J. Neurosci. 16, 1324-1336. doi: 10.1523/JNEUROSCI.16-04-01324.1996

Bjorkqvist, M., Wild, E. J., Thiele, J., Silvestroni, A., Andre, R., Lahiri, N., et al. (2008). A novel pathogenic pathway of immune activation detectable before clinical onset in Huntington's disease. J. Exp. Med. 205, 1869-1877. doi: 10. 1084/jem.20080178

Block, M. L., Zecca, L., and Hong, J. S. (2007). Microglia-mediated neurotoxicity: uncovering the molecular mechanisms. Nat. Rev. Neurosci. 8, 57-69. doi: 10. $1038 / \mathrm{nrn} 2038$

Blumenstock, S., and Dudanova, I. (2020). Cortical and striatal circuits in Huntington's disease. Front. Neurosci. 14:82. doi: 10.3389/fnins.2020.00082

Bogdanov, M. B., Andreassen, O. A., Dedeoglu, A., Ferrante, R. J., and Beal, M. F. (2001). Increased oxidative damage to DNA in a transgenic mouse model of Huntington's disease. J. Neurochem. 79, 1246-1249. doi: 10.1046/j.1471-4159. 2001.00689.x

Bono-Yagüe, J., Gómez-Escribano, A. P., Millán, J. M., and Vázquez-Manrique, R. P. (2020). Reactive species in Huntington disease: Are they really the radicals you want to catch? Antioxidants 9:577. doi: 10.3390/antiox9070577

Brennan, A. M., Suh, S. W., Won, S. J., Narasimhan, P., Kauppinen, T. M., Lee, H., et al. (2009). NADPH oxidase is the primary source of superoxide induced by NMDA receptor activation. Nat. Neurosci. 12, 857-863. doi: 10.1038/nn.2334

Brennan-Minnella, A. M., Shen, Y., El-Benna, J., and Swanson, R. A. (2013). Phosphoinositide 3-kinase couples NMDA receptors to superoxide release in excitotoxic neuronal death. Cell Death Dis. 4:e580. doi: 10.1038/cddis.2013.111

Bresgen, N., and Eckl, P. M. (2015). Oxidative stress and the homeodynamics of iron metabolism. Biomolecules 5, 808-847. doi: 10.3390/biom5020808

Brito, V., Giralt, A., Enriquez-Barreto, L., Puigdellívol, M., Suelves, N., ZamoraMoratalla, A., et al. (2014). Neurotrophin receptor p75(NTR) mediates Huntington's disease-associated synaptic and memory dysfunction. J. Clin. Invest. 124, 4411-4428. doi: 10.1172/JCI74809

Brown, G. C., and Borutaite, V. (2012). There is no evidence that mitochondria are the main source of reactive oxygen species in mammalian cells. Mitochondrion 12, 1-4. doi: 10.1016/j.mito.2011.02.001

Brown, G. E., Stewart, M. Q., Bissonnette, S. A., Elia, A. E., Wilker, E., and Yaffe, M. B. (2004). Distinct ligand-dependent roles for p38 MAPK in priming and activation of the neutrophil NADPH oxidase. J. Biol. Chem. 279, 27059-27068. doi: 10.1074/jbc.M314258200

Campanucci, V. A., Krishnaswamy, A., and Cooper, E. (2008). Mitochondrial reactive oxygen species inactivate neuronal nicotinic acetylcholine receptors and induce long-term depression of fast nicotinic synaptic transmission. J. Neurosci. 28, 1733-1744. doi: 10.1523/JNEUROSCI.5130-07.2008

Caviston, J. P., Ross, J. L., Antony, S. M., Tokito, M., and Holzbaur, E. L. (2007). Huntingtin facilitates dynein/dynactin-mediated vesicle transport. Proc. Natl. Acad. Sci. U.S.A. 104, 10045-10050. doi: 10.1073/pnas.0610628104

Cepeda, C., and Levine, M. S. (2020). Synaptic dysfunction in Huntington's disease: lessons from genetic animal models. Neuroscientist. [Epub ahead of print]. doi: $10.1177 / 1073858420972662$

Cheng, G., Ritsick, D., and Lambeth, J. D. (2004). Nox3 regulation by NOXO1, p47phox, and p67phox. J. Biol. Chem. 279, 34250-34255. doi: 10.1074/jbc. M400660200 
Cheret, C., Gervais, A., Lelli, A., Colin, C., Amar, L., Ravassard, P., et al. (2008). Neurotoxic activation of microglia is promoted by a nox1-dependent NADPH oxidase. J. Neurosci. 28, 12039-12051. doi: 10.1523/JNEUROSCI.3568-08. 2008

Coddou, C., Codocedo, J. F., Li, S., Lillo, J. G., Acuña-Castillo, C., Bull, P., et al. (2009). Reactive oxygen species potentiate the P2X2 receptor activity through intracellular Cys430. J. Neurosci. 29, 12284-12291. doi: 10.1523/JNEUROSCI. 2096-09.2009

Coleman, C. G., Wang, G., Faraco, G., Marques Lopes, J., Waters, E. M., Milner, T. A., et al. (2013). Membrane trafficking of NADPH oxidase p47(phox) in paraventricular hypothalamic neurons parallels local free radical production in angiotensin II slow-pressor hypertension. J. Neurosci. 33, 4308-4316. doi: 10.1523/JNEUROSCI.3061-12.2013

Collingridge, G. L., Peineau, S., Howland, J. G., and Wang, Y. T. (2010). Long-term depression in the CNS. Nat. Rev. Neurosci. 11, 459-473. doi: 10.1038/nrn2867

Conforti, P., Besusso, D., Bocchi, V. D., Faedo, A., Cesana, E., Rossetti, G., et al. (2018). Faulty neuronal determination and cell polarization are reverted by modulating HD early phenotypes. Proc. Natl. Acad. Sci. U.S.A. 115, E762-E771. doi: $10.1073 /$ pnas. 1715865115

Crotti, A., Benner, C., Kerman, B. E., Gosselin, D., Lagier-Tourenne, C., Zuccato, C., et al. (2014). Mutant Huntingtin promotes autonomous microglia activation via myeloid lineage-determining factors. Nat. Neurosci. 17, 513-521. doi: 10. 1038/nn.3668

Cui, L., Jeong, H., Borovecki, F., Parkhurst, C. N., Tanese, N., and Krainc, D. (2006). Transcriptional repression of PGC-1alpha by mutant huntingtin leads to mitochondrial dysfunction and neurodegeneration. Cell 127, 59-69. doi: 10.1016/j.cell.2006.09.015

Cummings, D. M., Milnerwood, A. J., Dallerac, G. M., Vatsavayai, S. C., Hirst, M. C., and Murphy, K. P. (2007). Abnormal cortical synaptic plasticity in a mouse model of Huntington's disease. Brain Res. Bull. 72, 103-107. doi: 10.1016/j.brainresbull.2006.10.016

Czeredys, M. (2020). Dysregulation of neuronal calcium signaling via storeoperated channels in Huntington's disease. Front. Cell. Dev. Biol. 8:611735. doi: $10.3389 /$ fcell.2020.611735

Dallérac, G. M., Vatsavayai, S. C., Cummings, D. M., Milnerwood, A. J., Peddie, C. J., Evans, K. A., et al. (2011). Impaired long-term potentiation in the prefrontal cortex of Huntington's disease mouse models: rescue by D1 dopamine receptor activation. Neurodegener. Dis. 8, 230-239. doi: 10.1159/ 000322540

Dang, P. M., Stensballe, A., Boussetta, T., Raad, H., Dewas, C., Kroviarski, Y., et al. (2006). A specific p47phox -serine phosphorylated by convergent MAPKs mediates neutrophil NADPH oxidase priming at inflammatory sites. J. Clin. Invest. 116, 2033-2043. doi: 10.1172/JCI27544

Di Filippo, M., de Iure, A., Giampà, C., Chiasserini, D., Tozzi, A., Orvietani, P. L., et al. (2016). Persistent activation of microglia and NADPH oxidase [corrected] drive hippocampal dysfunction in experimental multiple sclerosis. Sci. Rep. 6:20926. doi: 10.1038/srep23855

Di Maio, R., Mastroberardino, P. G., Hu, X., Montero, L., and Greenamyre, J. T. (2011). Pilocapine alters NMDA receptor expression and function in hippocampal neurons: NADPH oxidase and ERK1/2 mechanisms. Neurobiol. Dis. 42, 482-495. doi: 10.1016/j.nbd.2011.02.012

Ejlerskov, P., Christensen, D. P., Beyaie, D., Burritt, J. B., Paclet, M. H., Gorlach, A., et al. (2012). NADPH oxidase is internalized by clathrin-coated pits and localizes to a Rab27A/B GTPase-regulated secretory compartment in activated macrophages. J. Biol. Chem. 287, 4835-4852. doi: 10.1074/jbc.M111.293696

Ellson, C., Davidson, K., Anderson, K., Stephens, L. R., and Hawkins, P. T. (2006). PtdIns3P binding to the PX domain of p40phox is a physiological signal in NADPH oxidase activation. EMBO J. 25, 4468-4478. doi: 10.1038/sj.emboj. 7601346

Fão, L., and Rego, A. C. (2021). Mitochondrial and redox-based therapeutic strategies in Huntington's disease. Antioxid. Redox Signal. 34, 650-673. doi: 10.1089/ars.2019.8004

Fellner, L., Irschick, R., Schanda, K., Reindl, M., Klimaschewski, L., Poewe, W., et al. (2012). Toll-like receptor 4 is required for alpha-synuclein dependent activation of microglia and astroglia. Glia 2012:22437. doi: 10.1002/glia.22437

Fontayne, A., Dang, P. M., Gougerot-Pocidalo, M. A., and El-Benna, J. (2002). Phosphorylation of p47phox sites by PKC alpha, beta II, delta, and zeta: effect on binding to p22phox and on NADPH oxidase activation. Biochemistry 41, 7743-7750. doi: 10.1021/bi011953s

Gerdeman, G. L., Ronesi, J., and Lovinger, D. M. (2002). Postsynaptic endocannabinoid release is critical to long-term depression in the striatum. Nat. Neurosci. 5, 446-451. doi: 10.1038/nn832

Ghiglieri, V., Campanelli, F., Marino, G., Natale, G., Picconi, B., and Calabresi, P. (2019). Corticostriatal synaptic plasticity alterations in the R6/1 transgenic mouse model of Huntington's disease. J. Neurosci. Res. 97, 1655-1664. doi: 10.1002/jnr.24521

Ghilan, M., Bostrom, C. A., Hryciw, B. N., Simpson, J. M., Christie, B. R., and Gil-Mohapel, J. (2014). YAC128 Huntington's disease transgenic mice show enhanced short-term hippocampal synaptic plasticity early in the course of the disease. Brain Res. 1581, 117-128. doi: 10.1016/j.brainres.2014.06.011

Gianni, D., Diaz, B., Taulet, N., Fowler, B., Courtneidge, S. A., and Bokoch, G. M. (2009). Novel p47(phox)-related organizers regulate localized NADPH oxidase 1 (Nox1) activity. Sci. Signal. 2:ra54. doi: 10.1126/scisignal.2000370

Giralt, A., Saavedra, A., Carretón, O., Xifró, X., Alberch, J., and Pérez-Navarro, E. (2011). Increased PKA signaling disrupts recognition memory and spatial memory: role in Huntington's disease. Hum. Mol. Genet. 20, 4232-4247. doi: $10.1093 / \mathrm{hmg} / \mathrm{ddr} 351$

Girouard, H., Wang, G., Gallo, E. F., Anrather, J., Zhou, P., Pickel, V. M., et al. (2009). NMDA receptor activation increases free radical production through nitric oxide and NOX2. J. Neurosci. 29, 2545-2552. doi: 10.1523/JNEUROSCI. 0133-09.2009

Glass, M. J., Huang, J., Oselkin, M., Tarsitano, M. J., Wang, G., Iadecola, C., et al. (2006). Subcellular localization of nicotinamide adenine dinucleotide phosphate oxidase subunits in neurons and astroglia of the rat medial nucleus tractus solitarius: relationship with tyrosine hydroxylase immunoreactive neurons. Neuroscience 143, 547-564. doi: 10.1016/j.neuroscience.2006.08.051

Gunawardena, S., Her, L. S., Brusch, R. G., Laymon, R. A., Niesman, I. R., Gordesky-Gold, B., et al. (2003). Disruption of axonal transport by loss of huntingtin or expression of pathogenic polyQ proteins in Drosophila. Neuron 40, 25-40. doi: 10.1016/S0896-6273(03)00594-4

Han, I., You, Y., Kordower, J. H., Brady, S. T., and Morfini, G. A. (2010). Differential vulnerability of neurons in Huntington's disease: the role of cell type-specific features. J. Neurochem. 113, 1073-1091. doi: 10.1111/j.1471-4159.2010.06672.x

Hanisch, U. K., and Kettenmann, H. (2007). Microglia: active sensor and versatile effector cells in the normal and pathologic brain. Nat. Neurosci. 10, 1387-1394. doi: $10.1038 / \mathrm{nn} 1997$

Hardingham, G. E. (2009). Coupling of the NMDA receptor to neuroprotective and neurodestructive events. Biochem. Soc. Trans. 37, 1147-1160. doi: 10.1042/ BST0371147

Hardingham, G. E., and Bading, H. (2010). Synaptic versus extrasynaptic NMDA receptor signalling: implications for neurodegenerative disorders. Nat. Rev. Neurosci. 11, 682-696. doi: 10.1038/nrn2911

Hardingham, G. E., and Do, K. Q. (2016). Linking early-life NMDAR hypofunction and oxidative stress in schizophrenia pathogenesis. Nat. Rev. Neurosci. 17, 125-134. doi: 10.1038/nrn.2015.19

Helmcke, I., Heumüller, S., Tikkanen, R., Schröder, K., and Brandes, R. P. (2009). Identification of structural elements in Noxl and Nox4 controlling localization and activity. Antioxid. Redox Signal. 11, 1279-1287. doi: 10.1089/ars.2008. 2383

Heng, M. Y., Detloff, P. J., Wang, P. L., Tsien, J. Z., and Albin, R. L. (2009). In vivo evidence for NMDA receptor-mediated excitotoxicity in a murine genetic model of Huntington disease. J. Neurosci. 29, 3200-3205. doi: 10.1523/ JNEUROSCI.5599-08.2009

Hervera, A., De Virgiliis, F., Palmisano, I., Zhou, L., Tantardini, E., Kong, G., et al. (2018). Publisher Correction: reactive oxygen species regulate axonal regeneration through the release of exosomal NADPH oxidase 2 complexes into injured axons. Nat. Cell Biol. 20, 307-319. doi: 10.1038/s41556-018-0039-x

Hodgson, J. G., Agopyan, N., Gutekunst, C. A., Leavitt, B. R., LePiane, F., Singaraja, R., et al. (1999). A YAC mouse model for Huntington's disease with full-length mutant huntingtin, cytoplasmic toxicity, and selective striatal neurodegeneration. Neuron 23, 181-192. doi: 10.1016/S0896-6273(00)80 764-3

Hoerder-Suabedissen, A., Korrell, K. V., Hayashi, S., Jeans, A., Ramirez, D. M. O., Grant, E., et al. (2019). Cell-specific loss of SNAP25 from cortical projection 
neurons allows normal development but causes subsequent neurodegeneration. Cereb. Cortex 29, 2148-2159. doi: 10.1093/cercor/bhy127

Hoyal, C. R., Gutierrez, A., Young, B. M., Catz, S. D., Lin, J. H., Tsichlis, P. N., et al. (2003). Modulation of p47PHOX activity by site-specific phosphorylation: Aktdependent activation of the NADPH oxidase. Proc. Natl. Acad. Sci. U.S.A. 100, 5130-5135. doi: 10.1073/pnas.1031526100

Hung, R. J., Pak, C. W., and Terman, J. R. (2011). Direct redox regulation of F-actin assembly and disassembly by Mical. Science 334, 1710-1713. doi: 10 . 1126/science. 1211956

Hung, R. J., Yazdani, U., Yoon, J., Wu, H., Yang, T., Gupta, N., et al. (2010). Mical links semaphorins to F-actin disassembly. Nature 463, 823-827. doi: 10.1038 /nature 08724

Ibi, M., Katsuyama, M., Fan, C., Iwata, K., Nishinaka, T., Yokoyama, T., et al. (2006). NOX1/NADPH oxidase negatively regulates nerve growth factorinduced neurite outgrowth. Free Radic. Biol. Med. 40, 1785-1795. doi: 10.1016/ j.freeradbiomed.2006.01.009

Ikeda, S., Yamaoka-Tojo, M., Hilenski, L., Patrushev, N. A., Anwar, G. M., Quinn, M. T., et al. (2005). IQGAP1 regulates reactive oxygen species-dependent endothelial cell migration through interacting with Nox2. Arterioscler. Thromb. Vasc. Biol. 25, 2295-2300. doi: 10.1161/01.ATV.0000187472.55437.af

Jones, D. P., and Sies, H. (2015). The redox code. Antioxid. Redox Signal. 23, 734-746. doi: 10.1089/ars.2015.6247

Kallenborn-Gerhardt, W., Hohmann, S. W., Syhr, K. M., Schroder, K., Sisignano, M., Weigert, A., et al. (2014). Nox2-dependent signaling between macrophages and sensory neurons contributes to neuropathic pain hypersensitivity. Pain 155 , 2161-2170. doi: 10.1016/j.pain.2014.08.013

Kallenborn-Gerhardt, W., Schroder, K., Del Turco, D., Lu, R., Kynast, K., Kosowski, J., et al. (2012). NADPH oxidase-4 maintains neuropathic pain after peripheral nerve injury. J. Neurosci. 32, 10136-10145. doi: 10.1523/ JNEUROSCI.6227-11.2012

Kallenborn-Gerhardt, W., Schroder, K., Geisslinger, G., and Schmidtko, A. (2013). NOXious signaling in pain processing. Pharmacol. Ther. 137, 309-317. doi: 10.1016/j.pharmthera.2012.11.001

Kamat, C. D., Gadal, S., Mhatre, M., Williamson, K. S., Pye, Q. N., and Hensley, K. (2008). Antioxidants in central nervous system diseases: preclinical promise and translational challenges. J. Alzheimers Dis. 15, 473-493. doi: 10.3233/JAD2008-15314

Kamsler, A., and Segal, M. (2003). Hydrogen peroxide modulation of synaptic plasticity. J. Neurosci. 23, 269-276. doi: 10.1523/JNEUROSCI.23-01-00269. 2003

Kettenmann, H., Kirchhoff, F., and Verkhratsky, A. (2013). Microglia: new roles for the synaptic stripper. Neuron 77, 10-18. doi: 10.1016/j.neuron.2012.12.023

Kim, A., García-García, E., Straccia, M., Comella-Bolla, A., Miguez, A., Masana, M., et al. (2020). Reduced Fractalkine levels lead to striatal synaptic plasticity deficits in Huntington's Disease. Front. Cell. Neurosci. 14:163. doi: 10.3389/fncel.2020. 00163

Kishida, K. T., Hoeffer, C. A., Hu, D., Pao, M., Holland, S. M., and Klann, E. (2006). Synaptic plasticity deficits and mild memory impairments in mouse models of chronic granulomatous disease. Mol. Cell. Biol. 26, 5908-5920. doi: 10.1128/MCB.00269-06

Knapp, L. T., and Klann, E. (2002). Potentiation of hippocampal synaptic transmission by superoxide requires the oxidative activation of protein kinase C. J. Neurosci. 22, 674-683. doi: 10.1523/JNEUROSCI.22-03-00674. 2002

Kokovay, E., Wang, Y., Kusek, G., Wurster, R., Lederman, P., Lowry, N., et al. (2012). VCAM1 is essential to maintain the structure of the SVZ niche and acts as an environmental sensor to regulate SVZ lineage progression. Cell Stem Cell 11, 220-230. doi: 10.1016/j.stem.2012.06.016

Kraft, A. D., Kaltenbach, L. S., Lo, D. C., and Harry, G. J. (2012). Activated microglia proliferate at neurites of mutant huntingtin-expressing neurons. Neurobiol. Aging 33, 621.e17-621.e33. doi: 10.1016/j.neurobiolaging.2011.02.015

Kung, V. W., Hassam, R., Morton, A. J., and Jones, S. (2007). Dopamine-dependent long term potentiation in the dorsal striatum is reduced in the R6/2 mouse model of Huntington's disease. Neuroscience 146, 1571-1580. doi: 10.1016/j. neuroscience.2007.03.036

Kwan, W., Trager, U., Davalos, D., Chou, A., Bouchard, J., Andre, R., et al. (2012). Mutant huntingtin impairs immune cell migration in Huntington disease. J. Clin. Invest. 122, 4737-4747. doi: 10.1172/JCI64484
Lamb, F. S., Hook, J. S., Hilkin, B. M., Huber, J. N., Volk, A. P., and Moreland, J. G. (2012). Endotoxin priming of neutrophils requires endocytosis and NADPH oxidase-dependent endosomal reactive oxygen species. J. Biol. Chem. 287, 12395-12404. doi: 10.1074/jbc.M111.306530

Lambeth, J. D., and Neish, A. S. (2014). Nox enzymes and new thinking on reactive oxygen: a double-edged sword revisited. Annu. Rev. Pathol. 9, 119-145. doi: 10.1146/annurev-pathol-012513-104651

Le Belle, J. E., Orozco, N. M., Paucar, A. A., Saxe, J. P., Mottahedeh, J., Pyle, A. D., et al. (2011). Proliferative neural stem cells have high endogenous ROS levels that regulate self-renewal and neurogenesis in a PI3K/Akt-dependant manner. Cell Stem Cell 8, 59-71. doi: 10.1016/j.stem.2010.11.028

Lee, K. Y., Chung, K., and Chung, J. M. (2010). Involvement of reactive oxygen species in long-term potentiation in the spinal cord dorsal horn. J. Neurophysiol. 103, 382-391. doi: 10.1152/jn.90906.2008

Li, X., Marchal, C. C., Stull, N. D., Stahelin, R. V., and Dinauer, M. C. (2010). p47phox PX domain regulates plasma membrane but not phagosome neutrophil NADPH oxidase activation. J. Biol. Chem. 285, 35169-35179. doi: 10.1074/jbc.M110.164475

Lim, H., Kim, D., and Lee, S. J. (2013). Toll-like receptor 2 mediates peripheral nerve injury-induced NADPH oxidase 2 expression in spinal cord microglia. J. Biol. Chem. 288, 7572-7579. doi: 10.1074/jbc.M112.414904

Lipton, S. A., Choi, Y. B., Takahashi, H., Zhang, D., Li, W., Godzik, A., et al. (2002). Cysteine regulation of protein function-as exemplified by NMDA-receptor modulation. Trends Neurosci. 25, 474-480. doi: 10.1016/S0166-2236(02)02 245-2

Lu, S., and Lu, B. (2021). Degeneration versus development: hunting-out the D-Unit of Huntington's disease. Neurosci. Bull. 37, 757-760. doi: 10.1007/ s12264-021-00649-0

Luo, L., Kaur Kumar, J., and Clément, M. V. (2012). Redox control of cytosolic Akt phosphorylation in PTEN null cells. Free Radic. Biol. Med. 53, 1697-1707. doi: 10.1016/j.freeradbiomed.2012.08.566

Ma, B., Savas, J. N., Yu, M. S., Culver, B. P., Chao, M. V., and Tanese, N. (2011). Huntingtin mediates dendritic transport of beta-actin mRNA in rat neurons. Sci. Rep. 1:140. doi: 10.1038/srep00140

Maldonado, P. D., Molina-Jijón, E., Villeda-Hernández, J., Galván-Arzate, S., Santamaría, A., and Pedraza-Chaverrí, J. (2010). NAD(P)H oxidase contributes to neurotoxicity in an excitotoxic/prooxidant model of Huntington's disease in rats: protective role of apocynin. J. Neurosci. Res. 88, 620-629. doi: 10.1002/jnr. 22240

Malik, M., Parikh, I., Vasquez, J. B., Smith, C., Tai, L., Bu, G., et al. (2015). Genetics ignite focus on microglial inflammation in Alzheimer's disease. Mol. Neurodegener. 10:52. doi: 10.1186/s13024-015-0048-1

Martel, M. A., Wyllie, D. J., and Hardingham, G. E. (2009). In developing hippocampal neurons, NR2B-containing N-methyl-D-aspartate receptors (NMDARs) can mediate signaling to neuronal survival and synaptic potentiation, as well as neuronal death. Neuroscience 158, 334-343. doi: 10 . 1016/j.neuroscience.2008.01.080

Martinez-Vicente, M., Talloczy, Z., Wong, E., Tang, G., Koga, H., Kaushik, S., et al. (2010). Cargo recognition failure is responsible for inefficient autophagy in Huntington's disease. Nat. Neurosci. 13, 567-576. doi: 10.1038/nn.2528

Massaad, C. A., and Klann, E. (2011). Reactive oxygen species in the regulation of synaptic plasticity and memory. Antioxid. Redox Signal. 14, 2013-2054. doi: 10.1089 /ars.2010.3208

Mehta, S. R., Tom, C. M., Wang, Y., Bresee, C., Rushton, D., Mathkar, P. P., et al. (2018). Human Huntington's disease iPSC-derived cortical neurons display altered transcriptomics, morphology, and maturation. Cell Rep. 25, 1081-1096.e6. doi: 10.1016/j.celrep.2018.09.076

Miller, J., Arrasate, M., Shaby, B. A., Mitra, S., Masliah, E., and Finkbeiner, S. (2010). Quantitative relationships between huntingtin levels, polyglutamine length, inclusion body formation, and neuronal death provide novel insight into huntington's disease molecular pathogenesis. J. Neurosci. 30, 10541-10550. doi: 10.1523/JNEUROSCI.0146-10.2010

Milnerwood, A. J., Cummings, D. M., Dallérac, G. M., Brown, J. Y., Vatsavayai, S. C., Hirst, M. C., et al. (2006). Early development of aberrant synaptic plasticity in a mouse model of Huntington's disease. Hum. Mol. Genet. 15, 1690-1703. doi: 10.1093/hmg/ddl092

Milnerwood, A. J., and Raymond, L. A. (2007). Corticostriatal synaptic function in mouse models of Huntington's disease: early effects of huntingtin repeat 
length and protein load. J. Physiol. 585, 817-831. doi: 10.1113/jphysiol.2007.14 2448

Minnella, A. M., Zhao, J. X., Jiang, X., Jakobsen, E., Lu, F., Wu, L., et al. (2018). Excitotoxic superoxide production and neuronal death require both ionotropic and non-ionotropic NMDA receptor signaling. Sci. Rep. 8:17522. doi: 10.1038/ s41598-018-35725-5

Molero, A. E., Arteaga-Bracho, E. E., Chen, C. H., Gulinello, M., Winchester, M. L., Pichamoorthy, N., et al. (2016). Selective expression of mutant huntingtin during development recapitulates characteristic features of Huntington's disease. Proc. Natl. Acad. Sci. U.S.A. 113, 5736-5741. doi: 10.1073/pnas. 1603871113

Montoya, A., Pelletier, M., Menear, M., Duplessis, E., Richer, F., and Lepage, M. (2006). Episodic memory impairment in Huntington's disease: a meta-analysis. Neuropsychologia 44, 1984-1994. doi: 10.1016/j.neuropsychologia.2006.01.015

Moreland, J. G., Davis, A. P., Matsuda, J. J., Hook, J. S., Bailey, G., Nauseef, W. M., et al. (2007). Endotoxin priming of neutrophils requires NADPH oxidasegenerated oxidants and is regulated by the anion transporter ClC-3. J. Biol. Chem. 282, 33958-33967. doi: 10.1074/jbc.M705289200

Morfini, G. A., You, Y. M., Pollema, S. L., Kaminska, A., Liu, K., Yoshioka, K., et al. (2009). Pathogenic huntingtin inhibits fast axonal transport by activating JNK3 and phosphorylating kinesin. Nat. Neurosci. 12, 864-871. doi: 10.1038/nn.2346

Munnamalai, V., Weaver, C. J., Weisheit, C. E., Venkatraman, P., Agim, Z. S., Quinn, M. T., et al. (2014). Bidirectional interactions between NOX2-type NADPH oxidase and the F-actin cytoskeleton in neuronal growth cones. J. Neurochem. 130, 526-540. doi: 10.1111/jnc. 12734

Murphy, K. P., Carter, R. J., Lione, L. A., Mangiarini, L., Mahal, A., Bates, G. P., et al. (2000). Abnormal synaptic plasticity and impaired spatial cognition in mice transgenic for exon 1 of the human Huntington's disease mutation. J. Neurosci. 20, 5115-5123. doi: 10.1523/JNEUROSCI.20-13-05115.2000

Nauseef, W. M. (2019). The phagocyte NOX2 NADPH oxidase in microbial killing and cell signaling. Curr. Opin. Immunol. 60, 130-140. doi: 10.1016/j.coi.2019. 05.006

Nayernia, Z., Colaianna, M., Robledinos-Anton, N., Gutzwiller, E., Sloan-Bena, F., Stathaki, E., et al. (2017). Decreased neural precursor cell pool in NADPH oxidase 2-deficiency: From mouse brain to neural differentiation of patient derived iPSC. Redox Biol. 13, 82-93. doi: 10.1016/j.redox.2017.04.026

Nayernia, Z., Jaquet, V., and Krause, K. H. (2014). New insights on NOX enzymes in the central nervous system. Antioxid. Redox Signal. 20, 2815-2837. doi: 10.1089/ars.2013.5703

Oakley, F. D., Smith, R. L., and Engelhardt, J. F. (2009). Lipid rafts and caveolin1 coordinate interleukin-1beta (IL-1beta)-dependent activation of NFkappaB by controlling endocytosis of Nox2 and IL-1beta receptor 1 from the plasma membrane. J. Biol. Chem. 284, 33255-33264. doi: 10.1074/jbc.M109.042127

Olguin-Albuerne, M., and Moran, J. (2015). ROS produced by NOX2 control in vitro development of cerebellar granule neurons development. ASN Neuro 7:1759091415578712. doi: 10.1177/1759091415578712

Ooi, J., Langley, S. R., Xu, X., Utami, K. H., Sim, B., Huang, Y., et al. (2019). Unbiased profiling of isogenic Huntington disease hPSC-Derived CNS and peripheral cells reveals strong cell-type specificity of CAG length effects. Cell Rep. 26:2494. doi: 10.1016/j.celrep.2019.02.008

O’Regan, G. C., Farag, S. H., Casey, C. S., Wood-Kaczmar, A., Pocock, J. M., Tabrizi, S. J., et al. (2021). Human Huntington's disease pluripotent stem cellderived microglia develop normally but are abnormally hyper-reactive and release elevated levels of reactive oxygen species. J. Neuroinflammation 18:94. doi: 10.1186/s12974-021-02147-6

Oswald, M. C. W., Garnham, N., Sweeney, S. T., and Landgraf, M. (2018). Regulation of neuronal development and function by ROS. FEBS Lett. 592, 679-691. doi: 10.1002/1873-3468.12972

Park, H. S., Jung, H. Y., Park, E. Y., Kim, J., Lee, W. J., and Bae, Y. S. (2004). Cutting edge: direct interaction of TLR4 with $\mathrm{NAD}(\mathrm{P}) \mathrm{H}$ oxidase 4 isozyme is essential for lipopolysaccharide-induced production of reactive oxygen species and activation of NF-kappa B. J. Immunol. 173, 3589-3593. doi: 10.4049/ jimmunol.173.6.3589

Pavese, N., Gerhard, A., Tai, Y. F., Ho, A. K., Turkheimer, F., Barker, R. A., et al. (2006). Microglial activation correlates with severity in Huntington disease: a clinical and PET study. Neurology 66, 1638-1643. doi: 10.1212/01.wnl. 0000222734.56412 .17
Petersen, S. V., Poulsen, N. B., Linneberg Matthiesen, C., and Vilhardt, F. (2021). Novel and converging ways of NOX2 and SOD3 in trafficking and redox signaling in macrophages. Antioxidants 10:172. doi: 10.3390/antiox1002 0172

Petkau, T. L., Hill, A., Connolly, C., Lu, G., Wagner, P., Kosior, N., et al. (2019). Mutant huntingtin expression in microglia is neither required nor sufficient to cause the Huntington's disease-like phenotype in BACHD mice. Hum. Mol. Genet. 28, 1661-1670. doi: 10.1093/hmg/ddz009

Plotkin, J. L., Day, M., Peterson, J. D., Xie, Z., Kress, G. J., Rafalovich, I., et al. (2014). Impaired TrkB receptor signaling underlies corticostriatal dysfunction in Huntington's disease. Neuron 83, 178-188. doi: 10.1016/j.neuron.2014.05. 032

Plotkin, J. L., and Surmeier, D. J. (2015). Corticostriatal synaptic adaptations in Huntington's disease. Curr. Opin. Neurobiol. 33, 53-62. doi: 10.1016/j.conb. 2015.01.020

Price, M. O., Atkinson, S. J., Knaus, U. G., and Dinauer, M. C. (2002). Rac activation induces NADPH oxidase activity in transgenic COSphox cells and level of superoxide production is exchange factor-dependent. J. Biol. Chem. 277, 19220-19228. doi: 10.1074/jbc.M200061200

Qiao, H., Zhang, Q., Yuan, H., Li, Y., Wang, D., Wang, R., et al. (2015). Elevated neuronal alpha-synuclein promotes microglia activation after spinal cord ischemic/reperfused injury. Neuroreport 26, 656-661. doi: 10.1097/WNR. 0000000000000406

Qin, L., Liu, Y., Wang, T., Wei, S. J., Block, M. L., Wilson, B., et al. (2004). NADPH oxidase mediates lipopolysaccharide-induced neurotoxicity and proinflammatory gene expression in activated microglia. J. Biol. Chem. 279, 1415-1421. doi: 10.1074/jbc.M307657200

Quirion, J. G., and Parsons, M. P. (2019). The onset and progression of hippocampal synaptic plasticity deficits in the Q175FDN mouse model of Huntington disease. Front. Cell. Neurosci. 13:326. doi: 10.3389/fncel.2019. 00326

Ramdzan, Y. M., Trubetskov, M. M., Ormsby, A. R., Newcombe, E. A., Sui, X., Tobin, M. J., et al. (2017). Huntingtin inclusions trigger cellular quiescence, deactivate apoptosis, and lead to delayed necrosis. Cell Rep. 19, 919-927. doi: 10.1016/j.celrep.2017.04.029

Rey, F. E., Cifuentes, M. E., Kiarash, A., Quinn, M. T., and Pagano, P. J. (2001). Novel competitive inhibitor of $\mathrm{NAD}(\mathrm{P}) \mathrm{H}$ oxidase assembly attenuates vascular $\mathrm{O}(2)(-)$ and systolic blood pressure in mice. Circ. Res. 89, 408-414. doi: 10. 1161/hh1701.096037

Reyes, R. C., Brennan, A. M., Shen, Y., Baldwin, Y., and Swanson, R. A. (2012). Activation of neuronal NMDA receptors induces superoxide-mediated oxidative stress in neighboring neurons and astrocytes. J. Neurosci. 32, 1297312978. doi: 10.1523/JNEUROSCI.1597-12.2012

Rhee, S. G., Bae, Y. S., Lee, S. R., and Kwon, J. (2000). Hydrogen peroxide: a key messenger that modulates protein phosphorylation through cysteine oxidation. Sci. STKE 2000:e1. doi: 10.1126/scisignal.532000pe1

Roepstorff, K., Rasmussen, I., Sawada, M., Cudre-Maroux, C., Salmon, P., Bokoch, G., et al. (2008). Stimulus-dependent regulation of the phagocyte NADPH Oxidase by a VAV1, Rac1, and PAK1 Signaling Axis. J. Biol. Chem. 283, 7983-7993. doi: 10.1074/jbc.M708281200

Rui, Y. N., Xu, Z., Patel, B., Chen, Z., Chen, D., Tito, A., et al. (2015). Huntingtin functions as a scaffold for selective macroautophagy. Nat. Cell Biol. 17, 262-275. doi: $10.1038 / \mathrm{ncb} 3101$

Sapp, E., Seeley, C., Iuliano, M., Weisman, E., Vodicka, P., DiFiglia, M., et al. (2020). Protein changes in synaptosomes of Huntington's disease knock-in mice are dependent on age and brain region. Neurobiol. Dis. 141:104950. doi: 10.1016/j.nbd.2020.104950

Saudou, F., and Humbert, S. (2016). The biology of Huntingtin. Neuron 89, 910-926. doi: 10.1016/j.neuron.2016.02.003

Schiavone, S., Jaquet, V., Sorce, S., Dubois-Dauphin, M., Hultqvist, M., Backdahl, L., et al. (2012). NADPH oxidase elevations in pyramidal neurons drive psychosocial stress-induced neuropathology. Transl. Psychiatry 2:e111. doi: 10.1038/tp.2012.36

Sepers, M. D., Smith-Dijak, A., LeDue, J., Kolodziejczyk, K., Mackie, K., and Raymond, L. A. (2018). Endocannabinoid-specific impairment in synaptic plasticity in striatum of Huntington's Disease mouse model. J. Neurosci. 38, 544-554. doi: 10.1523/JNEUROSCI.1739-17.2017 
Serrander, L., Larsson, J., Lundqvist, H., Lindmark, M., Fallman, M., Dahlgren, C., et al. (1999). Particles binding beta(2)-integrins mediate intracellular production of oxidative metabolites in human neutrophils independently of phagocytosis. Biochim. Biophys. Acta 1452, 133-144. doi: 10.1016/S01674889(99)00123-8

Sies, H. (2014). Role of metabolic $\mathrm{H} 2 \mathrm{O} 2$ generation: redox signaling and oxidative stress. J. Biol. Chem. 289, 8735-8741. doi: 10.1074/jbc.R113.544635

Sies, H., and Jones, D. P. (2020). Reactive oxygen species (ROS) as pleiotropic physiological signalling agents. Nat. Rev. Mol. Cell Biol. 21, 363-383. doi: 10.1038/s41580-020-0230-3

Siew, J. J., Chen, H. M., Chen, H. Y., Chen, H. L., Chen, C. M., Soong, B. W., et al. (2019). Galectin-3 is required for the microglia-mediated brain inflammation in a model of Huntington's disease. Nat. Commun. 10:3473. doi: 10.1038/s41467019-11441-0

Singh, A., Kukreti, R., Saso, L., and Kukreti, S. (2019). Oxidative stress: a key modulator in neurodegenerative diseases. Molecules 24:1583. doi: 10.3390/ molecules 24081583

Singhrao, S. K., Neal, J. W., Morgan, B. P., and Gasque, P. (1999). Increased complement biosynthesis by microglia and complement activation on neurons in Huntington's disease. Exp. Neurol. 159, 362-376. doi: 10.1006/exnr.1999. 7170

Skotte, N. H., Andersen, J. V., Santos, A., Aldana, B. I., Willert, C. W., Nørremølle, A., et al. (2018). Integrative characterization of the R6/2 mouse model of Huntington's disease reveals dysfunctional astrocyte metabolism. Cell Rep. 23, 2211-2224. doi: 10.1016/j.celrep.2018.04.052

Smith, R., Klein, P., Koc-Schmitz, Y., Waldvogel, H. J., Faull, R. L., Brundin, P., et al. (2007). Loss of SNAP-25 and rabphilin $3 \mathrm{a}$ in sensory-motor cortex in Huntington's disease. J. Neurochem. 103, 115-123. doi: 10.1111/j.1471-4159. 2007.04703.x

Smith-Dijak, A. I., Sepers, M. D., and Raymond, L. A. (2019). Alterations in synaptic function and plasticity in Huntington disease. J. Neurochem. 150, 346-365. doi: 10.1111/jnc. 14723

Sorce, S., Stocker, R., Seredenina, T., Holmdahl, R., Aguzzi, A., Chio, A., et al. (2017). NADPH oxidases as drug targets and biomarkers in neurodegenerative diseases: What is the evidence? Free Radic. Biol. Med. 112, 387-396. doi: 10.1016/j.freeradbiomed.2017.08.006

Sorolla, M. A., Reverter-Branchat, G., Tamarit, J., Ferrer, I., Ros, J., and Cabiscol, E. (2008). Proteomic and oxidative stress analysis in human brain samples of Huntington disease. Free Radic. Biol. Med. 45, 667-678. doi: 10.1016/j. freeradbiomed.2008.05.014

Spence, E. F., and Soderling, S. H. (2015). Actin out: regulation of the synaptic cytoskeleton. J. Biol. Chem. 290, 28613-28622. doi: 10.1074/jbc.R115.65 5118

Stanton, P. K., Winterer, J., Bailey, C. P., Kyrozis, A., Raginov, I., Laube, G., et al. (2003). Long-term depression of presynaptic release from the readily releasable vesicle pool induced by NMDA receptor-dependent retrograde nitric oxide. J. Neurosci. 23, 5936-5944. doi: 10.1523/JNEUROSCI.23-13-05936.2003

St-Pierre, J., Drori, S., Uldry, M., Silvaggi, J. M., Rhee, J., Jäger, S., et al. (2006). Suppression of reactive oxygen species and neurodegeneration by the PGC1 transcriptional coactivators. Cell 127, 397-408. doi: 10.1016/j.cell.2006. 09.024

Su, Z., Burchfield, J. G., Yang, P., Humphrey, S. J., Yang, G., Francis, D., et al. (2019). Global redox proteome and phosphoproteome analysis reveals redox switch in Akt. Nat. Commun. 10:5486. doi: 10.1038/s41467-019-13114-4

Sumimoto, H., Hata, K., Mizuki, K., Ito, T., Kage, Y., Sakaki, Y., et al. (1996). Assembly and activation of the phagocyte NADPH oxidase. Specific interaction of the N-terminal Src homology 3 domain of p47phox with p22phox is required for activation of the NADPH oxidase. J. Biol. Chem. 271, 22152-22158. doi: $10.1074 /$ jbc. 271.36 .22152

Sun, Q. A., Hess, D. T., Nogueira, L., Yong, S., Bowles, D. E., Eu, J., et al. (2011). Oxygen-coupled redox regulation of the skeletal muscle ryanodine receptor$\mathrm{Ca} 2+$ release channel by NADPH oxidase 4. Proc. Natl. Acad. Sci. U.S.A. 108, 16098-16103. doi: 10.1073/pnas.1109546108

Suzukawa, K., Miura, K., Mitsushita, J., Resau, J., Hirose, K., Crystal, R., et al. (2000). Nerve growth factor-induced neuronal differentiation requires generation of Rac1-regulated reactive oxygen species. J. Biol. Chem. 275, 1317513178. doi: $10.1074 / j b c .275 .18 .13175$
Szlachcic, W. J., Switonski, P. M., Krzyzosiak, W. J., Figlerowicz, M., and Figiel, M. (2015). Huntington disease iPSCs show early molecular changes in intracellular signaling, the expression of oxidative stress proteins and the p53 pathway. Dis. Models Mech. 8, 1047-1057. doi: 10.1242/dmm.019406

Tai, Y. F., Pavese, N., Gerhard, A., Tabrizi, S. J., Barker, R. A., Brooks, D. J., et al. (2007). Microglial activation in presymptomatic Huntington's disease gene carriers. Brain 130, 1759-1766. doi: 10.1093/brain/awm044

Tejada-Simon, M. V., Serrano, F., Villasana, L. E., Kanterewicz, B. I., Wu, G. Y., Quinn, M. T., et al. (2005). Synaptic localization of a functional NADPH oxidase in the mouse hippocampus. Mol. Cell. Neurosci. 29, 97-106. doi: 10.1016/j.mcn. 2005.01.007

Tejera, D., and Heneka, M. T. (2019). Microglia in neurodegenerative disorders. Methods Mol. Biol. 2034, 57-67. doi: 10.1007/978-1-4939-9658-2_5

Teleanu, R. I., Chircov, C., Grumezescu, A. M., Volceanov, A., and Teleanu, D. M. (2019). Antioxidant therapies for neuroprotection-a review. J. Clin. Med. 8:1659. doi: $10.3390 / \mathrm{jcm} 8101659$

Terzi, A., Roeder, H., Weaver, C. J., and Suter, D. M. (2021). Neuronal NADPH oxidase 2 regulates growth cone guidance downstream of slit2/robo2. Dev. Neurobiol. 81, 3-21. doi: 10.1002/dneu.22791

Terzi, A., and Suter, D. M. (2020). The role of NADPH oxidases in neuronal development. Free Radic. Biol. Med. 154, 33-47. doi: 10.1016/j.freeradbiomed. 2020.04.027

The Huntington Disease Collaborative Research Group (1993). A novel gene containing a trinucleotide repeat that is expanded and unstable on Huntington's disease chromosomes. The Huntington's Disease Collaborative Research Group. Cell 72, 971-983. doi: 10.1016/0092-8674(93)90585-e

Thiels, E., Urban, N. N., Gonzalez-Burgos, G. R., Kanterewicz, B. I., Barrionuevo, G., Chu, C. T., et al. (2000). Impairment of long-term potentiation and associative memory in mice that overexpress extracellular superoxide dismutase. J. Neurosci. 20, 7631-7639. doi: 10.1523/JNEUROSCI.20-20-07631. 2000

Tousley, A., Iuliano, M., Weisman, E., Sapp, E., Richardson, H., Vodicka, P., et al. (2019a). Huntingtin associates with the actin cytoskeleton and $\alpha$-actinin isoforms to influence stimulus dependent morphology changes. PLoS One 14:e0212337. doi: 10.1371/journal.pone.0212337

Tousley, A., Iuliano, M., Weisman, E., Sapp, E., Zhang, N., Vodicka, P., et al. (2019b). Rac1 Activity is modulated by huntingtin and dysregulated in models of Huntington's disease. J. Huntingtons Dis. 8, 53-69. doi: 10.3233/JHD- 180311 Ueyama, T., Nakakita, J., Nakamura, T., Kobayashi, T., Kobayashi, T., Son, J., et al. (2011). Cooperation of p40phox with p47phox for Nox2based NADPH Oxidase Activation during Fcgamma Receptor (FcgammaR)mediated Phagocytosis: MECHANISM FOR ACQUISITION OF p40phox PHOSPHATIDYLINOSITOL 3-PHOSPHATE (PI(3)P) BINDING. J. Biol. Chem. 286, 40693-40705. doi: 10.1074/jbc.M111.237289

Usdin, M. T., Shelbourne, P. F., Myers, R. M., and Madison, D. V. (1999). Impaired synaptic plasticity in mice carrying the Huntington's disease mutation. Hum. Mol. Genet. 8, 839-846. doi: 10.1093/hmg/8.5.839

van der Plas, E., Schultz, J. L., and Nopoulos, P. C. (2020). The neurodevelopmental hypothesis of Huntington's Disease. J. Huntingtons Dis. 9, 217-229. doi: 10. 3233/JHD-200394

Vignais, P. V. (2002). The superoxide-generating NADPH oxidase: structural aspects and activation mechanism. Cell. Mol. Life Sci. 59, 1428-1459. doi: $10.1007 / \mathrm{s} 00018-002-8520-9$

Vilhardt, F., and van Deurs, B. (2004). The phagocyte NADPH oxidase depends on cholesterol-enriched membrane microdomains for assembly. EMBO J. 23, 739-748. doi: 10.1038/sj.emboj.7600066

Wang, G., Anrather, J., Huang, J., Speth, R. C., Pickel, V. M., and Iadecola, C. (2004). NADPH oxidase contributes to angiotensin II signaling in the nucleus tractus solitarius. J. Neurosci. 24, 5516-5524. doi: 10.1523/JNEUROSCI.117604.2004

Wang, J., and Swanson, R. A. (2020). Superoxide and non-ionotropic signaling in neuronal excitotoxicity. Front. Neurosci. 4:861. doi: 10.3389/fnins.2020.00861

Wang, Q., Rowan, M. J., and Anwyl, R. (2004). Beta-amyloid-mediated inhibition of NMDA receptor-dependent long-term potentiation induction involves activation of microglia and stimulation of inducible nitric oxide synthase and superoxide. J. Neurosci. 24, 6049-6056. doi: 10.1523/JNEUROSCI.0233-04. 2004 
Wang, S., Chu, C. H., Stewart, T., Ginghina, C., Wang, Y., Nie, H., et al. (2015). alpha-Synuclein, a chemoattractant, directs microglial migration via $\mathrm{H} 2 \mathrm{O} 2-$ dependent Lyn phosphorylation. Proc. Natl. Acad. Sci. U.S.A. 112, E1926E1935. doi: 10.1073/pnas.1417883112

Weaver, C. J., Terzi, A., Roeder, H., Gurol, T., Deng, Q., Leung, Y. F., et al. (2018). nox $2 /$ cybb deficiency affects zebrafish retinotectal connectivity. J. Neurosci. 38, 5854-5871. doi: 10.1523/JNEUROSCI.1483-16.2018

Weydt, P., Pineda, V. V., Torrence, A. E., Libby, R. T., Satterfield, T. F., Lazarowski, E. R., et al. (2006). Thermoregulatory and metabolic defects in Huntington's disease transgenic mice implicate PGC-1alpha in Huntington's disease neurodegeneration. Cell Metab. 4, 349-362. doi: 10.1016/j.cmet.2006. 10.004

Wilson, C., Munoz-Palma, E., Henriquez, D. R., Palmisano, I., Nunez, M. T., Di Giovanni, S., et al. (2016). A feed-forward mechanism involving the NOX complex and RyR-Mediated Ca2+ release during axonal specification. J. Neurosci. 36, 11107-11119. doi: 10.1523/JNEUROSCI.1455-16.2016

Wilson, C., Nunez, M. T., and Gonzalez-Billault, C. (2015). Contribution of $\mathrm{NADPH}$ oxidase to the establishment of hippocampal neuronal polarity in culture. J. Cell Sci. 128, 2989-2995. doi: 10.1242/jcs.168567

Wilton, D. K., and Stevens, B. (2020). The contribution of glial cells to Huntington's disease pathogenesis. Neurobiol. Dis. 143:104963. doi: 10.1016/j.nbd.2020. 104963

Winterbourn, C. C. (2008). Reconciling the chemistry and biology of reactive oxygen species. Nat. Chem. Biol. 4, 278-286. doi: 10.1038/nchembio.85

Winterbourn, C. C. (2013). The biological chemistry of hydrogen peroxide. Methods Enzymol. 528, 3-25. doi: 10.1016/B978-0-12-405881-1.00001-X

Woerner, A. C., Frottin, F., Hornburg, D., Feng, L. R., Meissner, F., Patra, M., et al. (2016). Cytoplasmic protein aggregates interfere with nucleocytoplasmic transport of protein and RNA. Science 351, 173-176. doi: 10.1126/science. $\operatorname{aad} 2033$

Wong, Y. C., and Holzbaur, E. L. (2014). The regulation of autophagosome dynamics by huntingtin and HAP1 is disrupted by expression of mutant huntingtin, leading to defective cargo degradation. J. Neurosci. 34, 1293-1305. doi: 10.1523/JNEUROSCI.1870-13.2014

Wu, J., Ryskamp, D. A., Liang, X., Egorova, P., Zakharova, O., Hung, G., et al. (2016). Enhanced Store-operated calcium entry leads to striatal synaptic loss in a Huntington's Disease mouse model. J. Neurosci. 36, 125-141. doi: 10.1523/ JNEUROSCI.1038-15.2016

Xu, J., Wei, X., Gao, F., Zhong, X., Guo, R., Ji, Y., et al. (2020). Nicotinamide adenine dinucleotide phosphate oxidase 2-derived reactive oxygen species contribute to long-term potentiation of C-fiber-evoked field potentials in spinal dorsal horn and persistent mirror-image pain following high-frequency stimulus of the sciatic nerve. Pain 161, 758-772. doi: 10.1097/j.pain. 0000000000001761

Xu, X., Tay, Y., Sim, B., Yoon, S. I., Huang, Y., Ooi, J., et al. (2017). Reversal of phenotypic abnormalities by CRISPR/Cas9-mediated gene correction in
Huntington disease patient-derived induced pluripotent stem cells. Stem Cell Rep. 8, 619-633. doi: 10.1016/j.stemcr.2017.01.022

Yi, J. H., Kim, D. H., Piers, T. M., Kim, S. C., Whitcomb, D. J., Regan, P., et al. (2018). Postsynaptic p47phox regulates long-term depression in the hippocampus. Cell Discov. 4:44. doi: 10.1038/s41421-018-0046-x

Yoneyama, M., Kawada, K., Gotoh, Y., Shiba, T., and Ogita, K. (2010). Endogenous reactive oxygen species are essential for proliferation of neural stem/progenitor cells. Neurochem. Int. 56, 740-746. doi: 10.1016/j.neuint.2009.11.018

Zamboni, V., Armentano, M., Berto, G., Ciraolo, E., Ghigo, A., Garzotto, D., et al. (2018). Hyperactivity of Racl-GTPase pathway impairs neuritogenesis of cortical neurons by altering actin dynamics. Sci. Rep. 8:7254. doi: 10.1038/ s41598-018-25354-3

Zhan, Y., Virbasius, J. V., Song, X., Pomerleau, D. P., and Zhou, G. W. (2002). The p40phox and p47phox PX domains of NADPH oxidase target cell membranes via direct and indirect recruitment by phosphoinositides. J. Biol. Chem. 277, 4512-4518. doi: 10.1074/jbc.M109520200

Zhang, D., Hu, X., Qian, L., Chen, S. H., Zhou, H., Wilson, B., et al. (2011). Microglial MAC1 receptor and PI3K are essential in mediating beta-amyloid peptide-induced microglial activation and subsequent neurotoxicity. J. Neuroinflammation 8:3. doi: 10.1186/1742-20 94-8-3

Zhang, J., Malik, A., Choi, H. B., Ko, R. W., Dissing-Olesen, L., and MacVicar, B. A. (2014). Microglial CR3 activation triggers long-term synaptic depression in the hippocampus via NADPH oxidase. Neuron 82, 195-207. doi: 10.1016/j.neuron. 2014.01.043

Zheng, J., Winderickx, J., Franssens, V., and Liu, B. (2018). A mitochondriaassociated oxidative stress perspective on Huntington's Disease. Front. Mol. Neurosci. 11:329. doi: 10.3389/fnmol.2018.00329

Conflict of Interest: The authors declare that the research was conducted in the absence of any commercial or financial relationships that could be construed as a potential conflict of interest.

Publisher's Note: All claims expressed in this article are solely those of the authors and do not necessarily represent those of their affiliated organizations, or those of the publisher, the editors and the reviewers. Any product that may be evaluated in this article, or claim that may be made by its manufacturer, is not guaranteed or endorsed by the publisher.

Copyright (c) 2021 Villegas, Nørremølle, Freude and Vilhardt. This is an openaccess article distributed under the terms of the Creative Commons Attribution License (CC BY). The use, distribution or reproduction in other forums is permitted, provided the original author(s) and the copyright owner(s) are credited and that the original publication in this journal is cited, in accordance with accepted academic practice. No use, distribution or reproduction is permitted which does not comply with these terms. 